\title{
Indigenous fertility in Australia: updating Alan Gray
}

\author{
Gordon A. Carmichael ${ }^{1}$
}

Published online: 20 September 2019

(c) The Author(s) 2019

\begin{abstract}
Although he was not the first scholar to investigate it, there is little question that the Ph.D. research of Alan Gray, completed in 1983, represented a landmark in the study of Indigenous fertility in Australia. Convinced that 'Aboriginal' fertility had fallen rapidly through the 1970 s, Gray set out to document and explain the decline. Weaving through a maze of sub-optimal census data he produced a series of agespecific and total fertility rates, refined by three broad geographic location categories, for 5-year periods from 1956-1961 to 1976-1981. These he subsequently updated to also include 1981-1986 and the 10-year period 1986-1996 as new census children-ever-borne data became available. He would doubtless have extended his series further had he lived to do so. For years his fertility estimates were graphed in the annual ABS publication Births Australia as the Bureau began publishing registration-based Indigenous fertility estimates from the late 1990s, but Indigenous birth registration data and fertility estimates based thereon remain to this day problematic in several respects. This paper summarises Alan Gray's work, extends his Indigenous fertility estimates to the 2011-2016 intercensal period, and examines the results against registration-based estimates that have been subjected to (a) regular retrospective revision (in light of data processing flaws and substantial errors of closure in intercensal Indigenous population increments), and (b) the vagaries of significant late registration, and periodic registry efforts to clear backlogs of unregistered Indigenous births.
\end{abstract}

Keywords Indigenous fertility $\cdot$ Aboriginal fertility $\cdot$ History $\cdot$ Aboriginal family formation $\cdot$ Children-ever-borne data $\cdot$ Birth registration data $\cdot$ Total fertility $\cdot$ Australia

Gordon A. Carmichael

gordon.carmichael@anu.edu.au

1 School of Demography, Australian National University, Canberra, ACT 2601, Australia 


\section{Introduction}

While not pretending there had been no prior literature on the topic (e.g., Jones $1963,1965,1970,1972,1973)$, there can be no question that a landmark in the study of Indigenous fertility in Australia was established by the Ph.D. research of Alan Gray (1983a). It was prompted by the appearance in the late 1970s of signs Aboriginal fertility had fallen sharply during that decade. Jones $(1965,1972)$ had estimated for the Northern Territory a rise in the Aboriginal total fertility rate (TFR) from 4.2 children per woman in 1958-1960 to well in excess of 6 children per woman in 1967-1968, speculating that a similar trend had probably occurred across Aboriginal Australia. Roughly concurring with Jones's latter figure, the National Population Inquiry (1975) estimated a national 1971 Indigenous TFR of 5.97 children per woman, although Gray's research would challenge Jones's finding of significant fertility increase during the 1960s.

The first hint that the Aboriginal birth rate was falling dramatically came indirectly from preliminary total population results from the 1976 Australian Census for collection districts predominantly populated by Indigenous people. In most there were fewer children aged 0-4 than 5-9, and within the younger age group fewer 0 year-olds than 1 year-olds, 1 year-olds than 2 year-olds, and so on. These patterns were subsequently confirmed by more detailed census data, holding wherever Aboriginal people were enumerated - in major urban areas, other urban areas, bounded rural localities and other rural localities. A Supplementary Report of the National Population Inquiry (1978: Table IV.4) added further evidence by producing from newly available data for the Northern Territory, Western Australia and Queensland crude birth rate estimates that showed appreciable decline through the 1970s. Any lingering doubt was then removed by first results of the 1981 Census, which showed many fewer Indigenous children aged 0-4 than 5-9, and 5-9 than 10-14.

In his thesis, Gray (1983a) set out to establish the extent of the Aboriginal fertility decline (he used the term 'Aboriginal' rather than 'Indigenous' consistently, but defined it to include Torres Strait Islanders) and concurrent reductions in infant and childhood mortality, all of which he associated with rapidly expanding health services in Aboriginal communities from the late 1960s and the provision in that context of contraceptive advice and supplies to Aboriginal women. Geographical variations and variations by age were also focused upon, and surveys in five Aboriginal communities sought to probe the attitudes and motivations of women concerning family planning. They were central to Gray's effort to do what previous scholars had failed to do, except speculatively: explain the downward trend. The surveys encountered extreme, culturally-founded reticence by women to discuss their reproductive lives, but reasons advanced for wanting or not wanting more children disclosed primarily household-level microeconomic fertility motivations. They were linked largely to changes brought about by improved educational opportunities for Aboriginal children, although these were appreciated more by the parental generation than by recipients of the education, among whom the traditional approach to family formation prioritising high fertility in adolescence and early adulthood continued to hold sway. 


\section{Background: history of Aboriginal fertility}

Gray (1983a) began his study by noting the dearth of historical data with which to study Aboriginal fertility:

The logical starting point for a study of Aboriginal fertility decline would be to consult official publications giving details over time of Aboriginal births throughout Australia, preferably classified by characteristics of the mothers such as their age, the number of children they had borne previously, geographical location and so on. There are no such official publications. Worse, the data which they should contain simply do not exist, except in isolated fragments. (Gray 1983a: 24)

Census data offered a limited alternative, suffering from a range of shortcomings that impacted any analysis of Aboriginal demographics. First, definitions of an Aborigine varied over time and place, excluded many with Aboriginal heritage, were at times logically inconsistent, and in implementation often failed to accurately capture conceptual populations targeted (Smith 1980b; Gray 1983a). Second, there had been marked under-enumeration of Aborigines due to deficient field processes, lack of field effort, exclusion (until a referendum in 1967 ended the practice) of 'full bloods' from the total population under section 127 of the Constitution, and discouragement from identifying as Aboriginal. In addition, census authorities had failed to process and publish, except intermittently in very rudimentary ways, data for Aborigines enumerated but then excluded under section 127; processing of data lacked consistency (e.g., in how race/racial origin/ indigenous origin 'not stated' was dealt with); and a tendency for single individuals, including mission/reserve authorities and census enumerators, to respond on behalf of all household members had seriously compromised personal identification as Aboriginal. Finally, until the 1966 Census no data on reproductive histories (children-ever-borne) had been collected.

For longer term historical census analysis of Aboriginal fertility, the only option is the child-woman ratio-the ratio of children aged 0-4 to women of reproductive age, 15-49. Such data are available, with caveats, through the twentieth century, but first, what of the preceding 100 + years of European presence and pre-contact times? It is generally held that a long-term balance between high birth rates and high death rates prior to 1788 is the only assumption compatible with the evidence of prolonged human habitation of Australia (Smith 1980b; Gray 1983a). Smith guessed that this balance might have been at about a level of 40 births and deaths per thousand population per annum. He was quickly challenged by anthropologist Cowlishaw (1981 1982), who argued that traditionally Aboriginal fertility was low. Malinowski (1913) had also noted much earlier that most observers concurred on a typical Aboriginal family size of two living children under the age of puberty, and that Aboriginal women breastfed for prolonged periods - at least 3 years and up to six —although a widely asserted high incidence of infanticide was probably exaggerated.

Cowlishaw's view was that Aboriginal women's diet and energy expenditure impeded ovulation and was the main factor limiting their fertility. They were 
much leaner than Aboriginal men, restricted in their access to food by cultural taboos that particularly affected young girls (conditioned early to accept inferior nourishment) and menstruating, pregnant and lactating women, and expected to prioritise their children's needs over their own. They contributed disproportionately to the daily labour of food acquisition, often from a position of demographic underrepresentation in tribal groups, being the sole gatherers of vegetables and shellfish, and hunters/catchers of small game. Other factors potentially limiting fertility allegedly included (1) coital frequencies constrained by lack of privacy, older men's priority access to younger women and polygamy; (2) extended lactation, the breast both nutrition source and pacifier, although its contraceptive effect had been exaggerated; (3) fallopian tube blockages arising from infection during first deliveries, abortions and pubertal introcision rituals; (4) cultural stress/ anxiety (e.g., in times of food shortage and post-contact), leading to anovulation and reduced sperm counts; (5) sub-incision practices leading to male infertility through infection and abstinence while healing; (6) foetal wastage associated with the physical demands of food collection and irregular diet; and (7) voluntary controls-periods of abstinence to avoid conception (medicines taken and rituals performed to this end were likely ineffective) and abortions. Cowlishaw also listed infanticide, but her conclusions as to its prevalence (Cowlishaw 1978) have more recently been vigorously disputed (Stephens 2003, 2014; Conor 2016).

Gray (1983b) drew attention to the fact that both Cowlishaw and Malinowski had focused not on fertility, but on family size. They were not the same, the latter determined by mortality rates as well as fertility rates, and also by family formations and reformations. He proceeded to demonstrate that small family size and high fertility could coexist, drawing on Daly River Mission baptismal register data for 1888-1901. This period was quite late in the post-contact era, but the Daly River, southwest of Darwin, was the frontier of European settlement at the time. Contact with Aborigines was recent, not extensive, and they were 'probably not under any concerted pressure' (Gray 1983b: 82). The baptismal register had 363 entries between 13 November, 1888 and 12 December, 1901, of which 211 pertained to newborn children. In 48 of those cases the mother also had been baptised, so her age at delivery was known and the distribution of those ages was consistent with a pattern of natural fertility (no evidence of fertility control). There were 92 cases of successive births of baptised babies with the same mother, for which the average intergenetic (between birth) interval was 34 months, and of women in the register known to be aged 15-49 about a third had given birth to no baptised children. Using these data (the latter an indicator of infecundity) and assuming natural fertility, Gray estimated a TFR of 9.0 children per woman, 'consistent with a crude birth rate somewhere in excess of 40 per thousand ... probably in the region of 56 per thousand' (Gray 1983b: 87-88).

How did this gel with anthropological contentions of relatively low fertility? Mortality! Of the 211 baptised children, 47 had died before they were a year old, another 15 before they turned two, and unknown numbers outside the 211 before baptisms could occur. An anthropologist visiting Daly River in 1901 would have found 76 women of fertile age with no children aged under 13, 65 with one, 23 with two, 7 with three, and none with four or more. 
... the high fertility assumption of Smith and the anthropologists' reports of low fertility are quite compatible in ... the Daly River data. ... The Daly River people did have high fertility, high enough to give a crude birth rate of well over 40 per thousand .... But very high levels of mortality in children under the age of two meant that the number of surviving children under the age of puberty was always small. Although it would be dangerous to generalise indiscriminately ... to all of Aboriginal Australia, [these] results ... do provide a reasonable path to ... explaining the apparent contradictions more generally. (Gray 1983b: 88-89)

So, to child-woman ratios (Table 1). It is important to appreciate that the childwoman ratio is a very crude measure of fertility. It takes no account of change over time in the age structure of the female population of reproductive age, which can see it rise or fall simply because peak reproductive ages become more or less prominent within that population. This in fact happened during 1966-1981. The high fertility 15-24 female age group became a larger proportion of the 15-49 age group, so that child-woman ratios understate the extent of fertility decline through the 1970s (Gray 1983a). The child-woman ratio is also highly sensitive to changes in rates of infant, early childhood or maternal mortality and hence survival. And in the study of Aboriginal fertility there is the further reality to be considered that not all Aboriginal children are born to Aboriginal mothers. Some are born to non-Aboriginal mothers by Aboriginal fathers, whence they contribute to child-woman ratio numerators, but their mothers are excluded from denominators. Thus, Aboriginal child-woman ratios inflate the fertility of Aboriginal women of reproductive age and may rise or fall partly because rates of ethnic intermarriage (interpartnering) increase or decrease, raising or lowering the proportion of Aboriginal 0-4 year-olds who are not progeny of Aboriginal women.

Table 1 shows mostly low child-woman ratios for the early twentieth century, and Gray (1983a) provides others, similarly low, for latter decades of the nineteenth century-339 for Victoria in 1871, 378 for New South Wales in 1891. These early values are indicative of birth rates below what was required to sustain positive population growth, but until 1966 data only cover people in settled areas, and beyond those areas, especially in Queensland, South Australia, Western Australia and the Northern Territory, child-woman ratios were probably higher. Gray (1983a), because of differences in census coverage of Aboriginal people between States/Territories and over time, chose not to include all-Australia values in his table on which Table 1 builds. Neither did he include data for 1921 and 1954, because no data for enumerated 'full bloods' were ever published for those censuses and available figures consequently pertain to 'half caste' Aborigines only. Issues of coverage are, however, less relevant over the post-1981 period for which data are updated here, so a decision to include all-Australia ratios has been made. It does not alter the need to be mindful of the limitations of earlier such ratios, and 1921 and 1954 figures have been italicized to reflect the particular element of non-comparability that applies to them. Note that for 1954 no State/Territory data at all are available.

Discounting the clearly non-comparable ratios for 1921 and 1954, all-Australia figures in Table 1 suggest progressively increasing fertility through the first half of the twentieth century to a plateau of around 800 (double and more what was 
Table 1 Aboriginal childwoman ratios by state/territory 1901-2016

\begin{tabular}{|c|c|c|c|c|c|c|c|c|c|}
\hline Year & NSW & VIC & QLD & S.A & W.A & TAS & N.T & ACT & AUST \\
\hline 1901 & 518 & 576 & 388 & & 207 & & & & 341 \\
\hline 1911 & 714 & 590 & 425 & 415 & 248 & 681 & 157 & & 416 \\
\hline 1921 & 808 & 573 & 709 & 544 & 336 & 727 & 520 & & 713 \\
\hline 1933 & 717 & 548 & 504 & 602 & 518 & 611 & 304 & & 521 \\
\hline 1947 & 801 & 702 & 623 & 718 & 504 & 641 & 479 & & 608 \\
\hline 1954 & & & & & & & & & 854 \\
\hline 1961 & 933 & 864 & 786 & 907 & 815 & 571 & 708 & & 808 \\
\hline 1966 & 922 & 722 & 782 & 836 & 836 & 400 & 735 & & 806 \\
\hline 1971 & 827 & 695 & 784 & 798 & 859 & 651 & 774 & & 799 \\
\hline 1976 & 595 & 535 & 633 & 536 & 675 & 599 & 676 & & 618 \\
\hline 1981 & 504 & 512 & 550 & 510 & 555 & 509 & 571 & & 539 \\
\hline 1986 & 532 & 491 & 524 & 547 & 546 & 541 & 518 & 507 & 529 \\
\hline 1991 & 569 & 563 & 563 & 546 & 614 & 553 & 561 & 513 & 570 \\
\hline 1996 & 579 & 547 & 570 & 520 & 521 & 511 & 499 & 498 & 549 \\
\hline 2001 & 538 & 505 & 515 & 481 & 498 & 485 & 442 & 471 & 505 \\
\hline 2006 & 500 & 482 & 517 & 448 & 463 & 451 & 442 & 434 & 485 \\
\hline 2011 & 497 & 495 & 521 & 458 & 451 & 493 & 392 & 416 & 483 \\
\hline 2016 & 492 & 494 & 490 & 458 & 449 & 448 & 359 & 441 & 469 \\
\hline
\end{tabular}

1. Figures for 1901-1981, except those for 1921 and 1954 and for Australia, are from Gray (1983a) and are census-enumerated figures. Those for 1986-2016 are based on Indigenous age-sex distributions as at June 30th in census years after adjustment for census undercount

2. Figures for 1921 and 1954 are for 'half caste' Aboriginals only, as no data for enumerated 'full bloods' were ever published for those years

3. ACT included with NSW 1901-1981

4. Figures for 1947 exclude Torres Strait Islanders, who were classified as 'Other Polynesians' and are not separately identifiable

5. Australian figure for 1901 excludes South Australia, Tasmania and the Northern Territory, for which data are not available

Source: Gray (1983a: Table 1); Australian Historical Population Statistics 2008 and 2014, ABS Catalogue 3105.0.65.001; 2016 Australian Census

recorded in 1901 and 1911) over the decade 1961-1971, before a sharp decline during 1971-1981, relative stability over the next decade and a half (save for a 1986-1991 spike), then further more gentle decline, especially during 1996-2001. The upsurge in ratios to 1961 reflects the recovery of Aboriginal fertility from depths to which it had plummeted by the turn of the twentieth century due to massive Aboriginal depopulation under colonialism (Smith 1980b), a process likely to reflect in part the transition of many Aborigines from nomadism to residence on missions and reserves. This arguably loosened some traditional constraints on Aboriginal fertility postulated by Cowlishaw (1981) and reduced infant and child mortality. State/ 
Territory differentials prior to World War 2 may also owe something to differences in the timing of this process. Cowlishaw suggests, for example, that women no longer being burdened by daily food gathering, dietary changes that boosted their body weight (chiefly greater consumption of flour and sugar), and the greater privacy for coitus afforded by living in buildings rather than in open-air camps all contributed. It is notable, too, that, as already intimated, Jones's $(1965,1972)$ finding of significant fertility increase through the 1960 s for the Northern Territory and probably for Australia is contradicted by the plateauing of fertility through that decade. Some increase for the Northern Territory is evident, but nothing like the $57 \%$ figure reported by Jones.

Discounting Tasmania because of its small Aboriginal population, child-woman ratios to 1947 tend to have been lowest in the Northern Territory, Western Australia and to a lesser extent Queensland, States/Territories with significant Aboriginal populations living beyond settled areas and so not covered by censuses, and highest in New South Wales/ACT and Victoria. Perhaps in the former States/Territories there was more separation of families, with some husbands/fathers employed in settled areas but their wives and children still living traditionally. During the 1960s New South Wales/ACT recorded the highest child-woman ratios, with Western Australian ratios consistently comparatively high from 1966 until 1991. Northern Territory ratios were the highest in 1976 and 1981 but excluding the ACT have been consistently the lowest since 1996 . This pattern may point to slightly slower fertility decline through the 1970s and clearly reflects a much lower inflation of child-woman ratios by Aboriginal children with non-Aboriginal mothers as interpartnering has increased more recently. Across the period 2001-2016 an annual average of just $7.6 \%$ of Indigenous births registered in the Northern Territory were to non-Indigenous mothers by Indigenous fathers. The national average, $27.8 \%$, was far higher, as were other State figures: New South Wales 34.0\%, Victoria 39.5\%, Queensland 27.4\%, South Australia 27.1\%, Western Australia 21.3\% and Tasmania 41.3\%.

\section{Aboriginal family formation}

Preparatory to undertaking his more detailed analysis of Aboriginal fertility decline during the 1970s, Gray (1983a, 1984) addressed the nature of Aboriginal family formation. While an extensive anthropological literature existed on Aboriginal kinship and custom, there was at that time a comparative dearth of description of the contemporary pattern of Aboriginal family formation. Custom related to marriage featured polygyny, large age differences between husbands and wives marrying for the first time, consequent frequent widowhood and remarriage, counter-cultures with rules and standardized procedures for extra-marital or informal intercourse, and marriage eligibility principles that emphasised non-consanguinity and a complicated structure of moieties, sections and subsections stipulating who could marry whom (Shapiro 1979). Moieties divided tribes in two, usually on the basis of patrilineal descent; sections and subsections then being intra-moiety totem groups identified with mythological ancestral beings, from which they derived names associated with 
natural phenomena-often animals or plants, but also things like wind, sun, water, rain or cloud.

Studies in the 1970s (Beasley 1970; Smith and Biddle 1975) had reported circumspection among Aboriginal people asked about their 'marriages', which often seemed to be de facto, and not infrequently serially so. Gray (1983a: 64) saw this as part of a phenomenon Kitaoji (1976) had labelled the 'myth of disorder in the Aboriginal family today' - the notion that it was unstable, promiscuous and lacked order. In his view descriptions of Aboriginal family formation across a range of geographical settings were remarkably similar. Its 'outstanding feature' was 'toleration of a range of types of sexual union-legal marriage, de facto marriage and casual liaisons' (Gray 1983a: 65). Bearing similarities to Caribbean customs but assumed by Aborigines to be disapproved of by European Australians (hence their circumspection), these types occurred in a logically ordered sequence. Casual liaison and pregnancy often preceded a first consensual union, which may or may not be permanent, and this in turn usually preceded legal marriage, if that occurred at all. Pregnancy and childbirth did not necessarily lead to consensual partnering, but neither did motherhood necessarily inhibit a woman's prospects of forming a permanent sexual union. 'The essential point', claimed Gray (p 66), was that this new pattern, because it was found everywhere, 'must be seen as a transformation of the [traditional tribal] pattern.'

There was little to distinguish marriages according to tribal custom from modern de facto marriages in Aboriginal eyes. They shared the invisible features of a lack of legal status and a relative absence of ceremony, and Gray proposed that either could be termed 'customary', as distinct from legal, marriages. His purpose in discussing the issue was to assess the extent to which nuptiality was relevant to an analysis of Aboriginal fertility. He proceeded to demonstrate major inconsistency across the 1966-1981 Censuses in age-specific proportions of Aboriginal women in major urban, other urban and rural areas who were classified as 'never married'. This involved (1) numerous instances of proportions increasing as 5-year cohorts aged (impossible if the marital status question was answered consistently from census to census by essentially the same women) and (2) implausibly variant proportions across censuses for some age groups (e.g., the percentage of 20-24 year-olds in major urban areas never married varying from 37 in 1971 to 67 in 1981). Gray concluded that there was considerable uncertainty as to the meaning of census data on Aboriginal marital statuses, but that they had little to do with legal marital status. He noted that of 347 Aboriginal births registered in Dubbo, the Far North Coast of New South Wales and Walgett during 1980-1982, 18\% had occurred to legally married women, $55 \%$ to customarily married women, and $26 \%$ to single women, a pattern in keeping with the sequential process of family formation described above.

\section{Aboriginal fertility estimates derived from census parity data}

The difficulty posed for Gray by the inconsistency of Aboriginal census marital status data was that it greatly complicated the analysis of census parity information for Aboriginal women. From this he wished to calculate, using the hypothetical cohort 
method of Zlotnik and Hill (1981), age-specific and total fertility rates for intercensal periods 1966-1971, 1971-1976 and 1976-1981, a series projected back to also embrace 1956-1961 and 1961-1966 by assuming the pattern of cohort change in mean parities during 1966-1971 was replicated over the preceding two 5-year periods. Zlotnik and Hill's method assumed a capacity to calculate census age-specific mean parities for all women. Unfortunately, however, when a children-ever-borne question was introduced at the 1966 Australian Census it was asked, probably for reasons of perceived sensitivity, only of currently married women and in respect only of children of the current marriage. The 1971 and 1976 censuses then asked ever married women about children borne in all marriages. Only in 1981 were all women finally asked about all children borne, the ideal question format. Gray was left with a very complex estimation exercise to produce, for all four censuses, the data the Zlotnik-Hill method required. It had to take account of both the exclusion of certain marital status groups and categories of children from 1966, 1971 and 1976 data, and the uncertainty as to how Aboriginal respondents at those three censuses had actually classified themselves as currently or ever married.

It is not proposed to retrace Gray's (1983a) detailed methodology here. Rather, in Table 2, are shown results of his work for the five periods listed above, along with updates he subsequently published for 1981-1986 (Gray 1990) and 1986-1996 (Gray 1997), and further updates for 1996-2006, 2006-2011 and 2011-2016 prepared as the primary contribution of this paper by the author. Ideally the ZlotnikHill method uses quinquennial census data to produce fertility estimates for 5-year intercensal periods. It subtracts the mean parity of all women aged $x$ to $x+4$ at one census from that of those aged $x+5$ to $x+9$ ( 5 years older) at the next census to obtain measures of intercensal change, which cumulated across all reproductive 5-year age group transitions yield an approximate intercensal TFR. The fact that two columns in Table 2 pertain to the decades 1986-1996 and 1996-2006 reflects decisions of the Australian Bureau of Statistics to not ask children-ever-borne questions at the 1991 and 2001 Censuses. The official ABS position over this period was that decennial data were adequate. Zlotnik and Hill do provide a modified method that yields fertility estimates for 10-year intercensal periods. It was used by Gray for 1986-1996 and by the author for 1996-2006. Note also that the periods 1956-1961 and 1961-1966 are not 'intercensal'. No children-ever-borne (CEB) data for 1956 or 1961 were available, and indeed 1956 was not even a census year (1954 was). Minimal intercensal change 1966-1971 was simply projected back two 5-year periods.

Gray's (1983a) initial analysis was geographically refined to differentiate between major urban, other urban and rural areas, and that geographic differentiation has been maintained in the author's updates with one modification. Between the 2006 and 2011 Censuses Darwin transitioned from an 'other' urban area to become a 'major' urban area, passing the minimum population threshold of 100,000. To maintain geographic comparability over time Darwin, as a significant Aboriginal population centre, has continued here to be treated as an 'other urban' area in both 2011 and 2016. It should also be noted that in his thesis Gray standardized total population results to the age and geographical distribution of Aboriginal women of reproductive age in 1981. In his subsequent updates (Gray 1990, 1997) he re-standardized to distributions in 1986 and 1996, in each case the most recent census incorporated, 


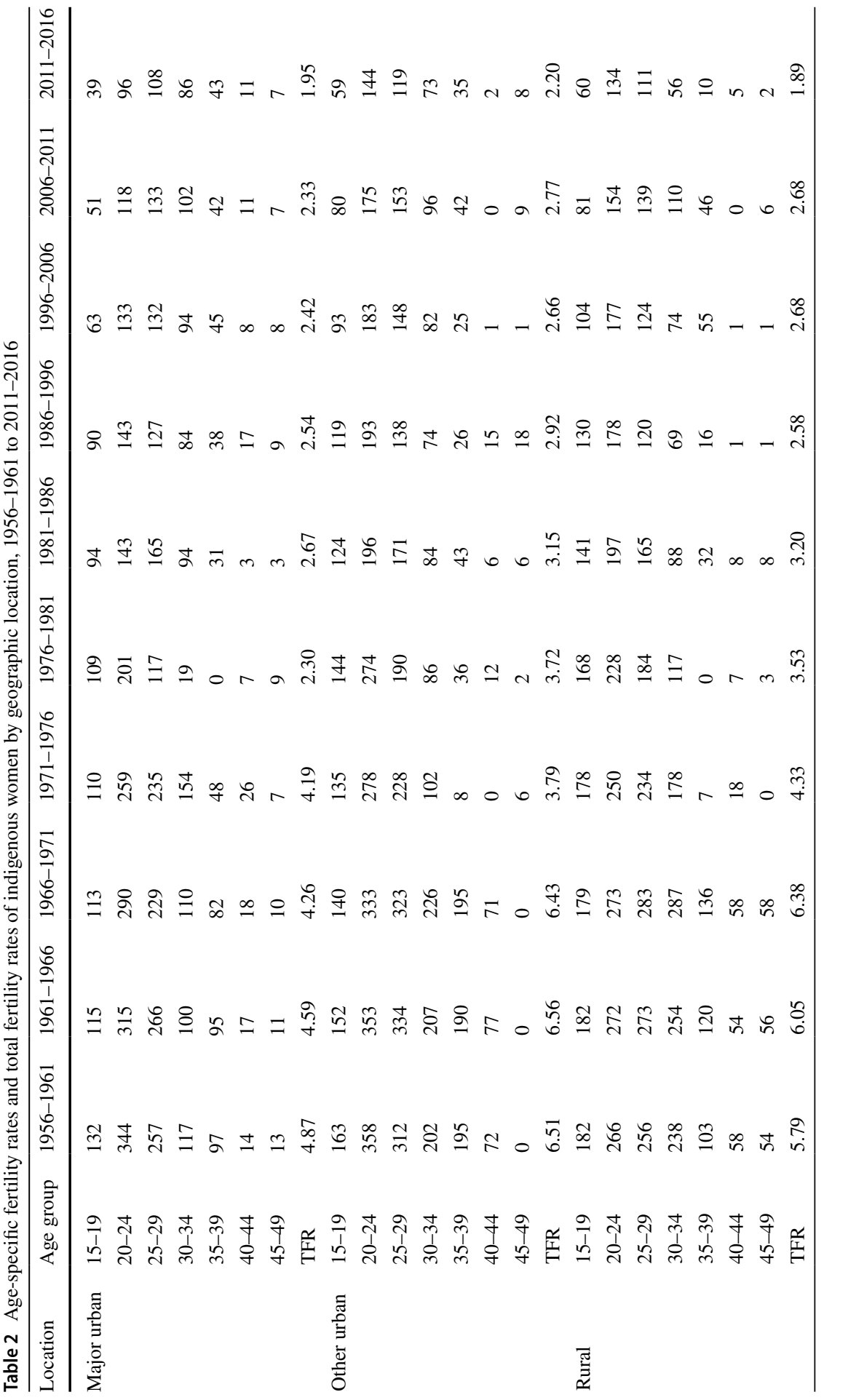




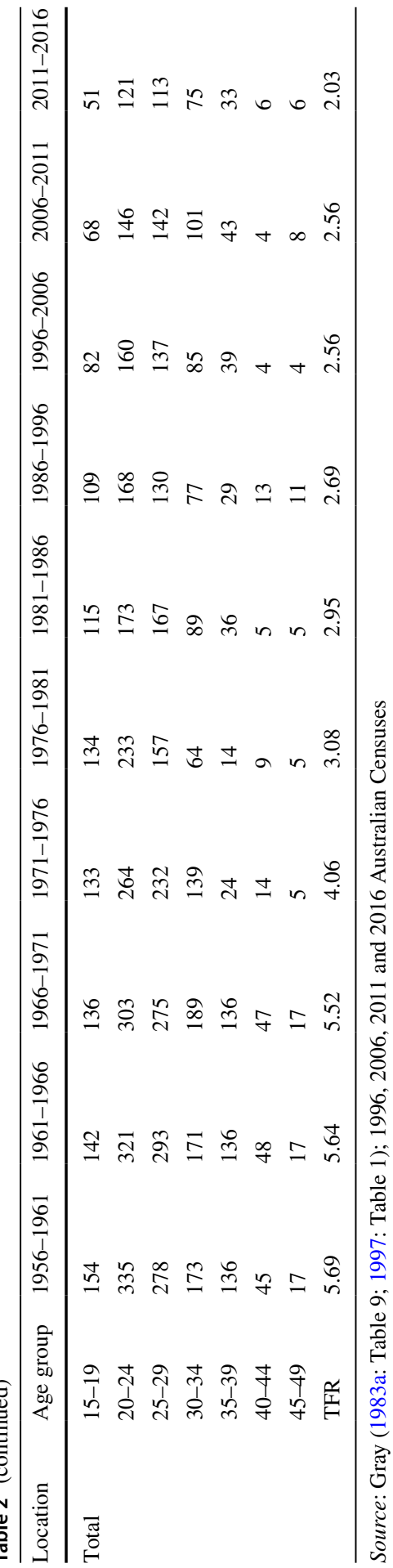


and continuing that practice total population results in Table 2 are standardized to the age and geographical distribution of Indigenous women in 2016. Standardization to different distributions in Gray's original analysis and succeeding updates results in minor changes of detail in total population fertility estimates for given periods, but broad features of trends over time are preserved. Disaggregated results for individual geographic categories (major urban, other urban and rural) do not change, and for any particular period are not strictly comparable with standardized total population estimates.

The first five columns of Table 2 present the major urban, other urban and rural results from Gray's thesis, along with total population estimates re-standardized to the 2016 distribution of Indigenous women by age and geographical location. Gray independently validated his 1956-1981 results in two ways, concluding that assumptions made in deriving them were highly plausible. The 'Total' TFR estimate for 1966-1971 (5.52 children per woman) fell by $44 \%$ to 3.08 children per woman in 1976-1981. This compares to a 33\% 1971-1981 decline in the child-woman ratio, which as noted previously understates the fertility decline because peak reproductive ages became more prominent within the 15-49 age group over this period and infant survival improved. Most of the fertility decline was attributable to a substantial drop above age 30. Ages 30-49 accounted for 35\% of total fertility in 1966-1971 but for under $15 \%$ in 1976-1981, the absolute decline in fertility at those ages over the decade being $76 \%$ ( $84 \%$ in major urban areas). The initial decline, between 1966-1971 and 1971-1976, was heavily concentrated at ages 35-39 and above, with limited further decline at those ages between 1971-1976 and 1976-1981. By contrast the decline at ages 30-34 was more spread across these two intervals, but larger during the second of them. Clearly older, presumably higher parity women in particular quickly seized the opportunity to terminate childbearing.

While there was also significant fertility decline at ages 20-29 between 1966-1971 and 1976-1981, at the lowest extremity of the reproductive age spectrum, ages 15-19, virtually none was recorded (Table 2), leading Gray (1983a: 92) to observe:

... the process of family formation in Aboriginal Australia provides strong props for high fertility of young women ... fertility is essential to Aboriginal family formation, not incidental or consequential [to it]. Whatever changes have occurred in recent years have affected the fertility of young women but little.

The steepness of the Aboriginal fertility decline above age 30 suggested explanation should be sought not in internal Aboriginal institutions, but in non-Aboriginal institutions interacting with Aboriginal communities. Obvious candidates were improved educational opportunities and expanded health services, particularly access the latter had provided to contraception. It was reasonable to surmise that provision of family planning services to older women had satisfied a previously unmet demand. Marked differences in patterns of Aboriginal fertility decline in different parts of Australia (Table 2) were also likely to reflect geographically variant interactions between Aboriginal and non-Aboriginal institutions. Decline was 
initially (to 1971-1976) concentrated in other urban and rural areas, a marked major urban catch-up then occurring between 1971-1976 and 1976-1981.

The reduction in Aboriginal fertility during the 1970s was accompanied by a similarly marked downturn in Aboriginal infant mortality. Revelation of very high levels of infant mortality during 1958-1960 in the Northern Territory (137 and 154 infant deaths per 1000 live male and female births (Jones 1965)) led to a demand for action. Smith (1980a) recorded a decline from 143 infant deaths per 1000 live births in the Northern Territory in 1971 to 50 per 1000 in 1975 and 48 per 1000 in 1978, and summarizing 'all available data' for 1965-1978 produced a trend line smoothing annual fluctuations that extended from 138 per 1000 in 1965 to 53 per 1000 in 1978. Thomson (1990) then published 1972-1974 to 1984-1986 declines from 74.3 to 32.5 per 1000 for the Northern Territory and from 78.4 to 21.3 per 1000 for a swathe of Queensland Aboriginal reserve communities, also citing a 1971 West Australian estimate of 76 per 1000 that compared to his estimate of 23 per 1000 by 1981-1983.

The two trends, reduced fertility and reduced infant mortality, in dynamic interaction during the 1970s were jointly linked to improved health services for mothers and babies. Childhood mortality probably also fell as a consequence of health service improvements, because it also tended to be lower where (geographically) infant mortality was lower (Gray 1983a). A causal link between the trends could not, however, plausibly be argued. As both had occurred suddenly and simultaneously, they had to reflect a common influence, which was 'clearly improvement of health services to Aboriginal people' (Gray 1983a: 253).

Once data from the 1986 Census became available, Gray (1990) was able to add the 1981-1986 intercensal period to his series of fertility rates (Table 2). The allAustralia TFR had fallen further from 3.08 children per woman to 2.95 and the other urban and rural TFRs had also dropped again (from 3.72 to 3.15 and from 3.53 to 3.20 respectively), but major urban fertility had increased from 2.30 to 2.67, principally due to resurgences at ages 25-29 and especially 30-34 and 35-39. Across Aboriginal Australia the main age-specific declines had been from 233 to 173 births per 1000 women at ages 20-24 (26\%) and from 134 to 115 per 1000 at ages 15-19 (14\%), the first appreciable decline for the latter age group and the first sign that the traditional Aboriginal family formation pattern favouring very early initiation of childbearing was beginning to be modified. Fertility had risen slightly at ages 25-29, 30-34 and 35-39, but as of the early 1980s Aboriginal fertility had fallen sufficiently at ages 25-29 and above to be not dissimilar to that for all Australian women. At younger ages, however, it remained appreciably higher than for all women (Fig. 1).

The failure to collect children-ever-borne data at the 1991 Census meant a hiatus in Gray's updating of his fertility estimates, one that saw other analytic approaches adopted, alternative data sources experimented with (e.g., Tesfaghiorghis 1996), and pressure intensified to bring Indigenous birth registration up to an acceptable standard (agitation to this end was frequent at meetings and conferences through and after the 1980s (Len Smith, pers. comm.)). Jain (1989) and Dugbaza (1994, 1995) produced 'own children' analyses of Aboriginal fertility, using 1986 and 1991 Census data respectively. The 'own children' method (Cho et al. 1986) matches children 


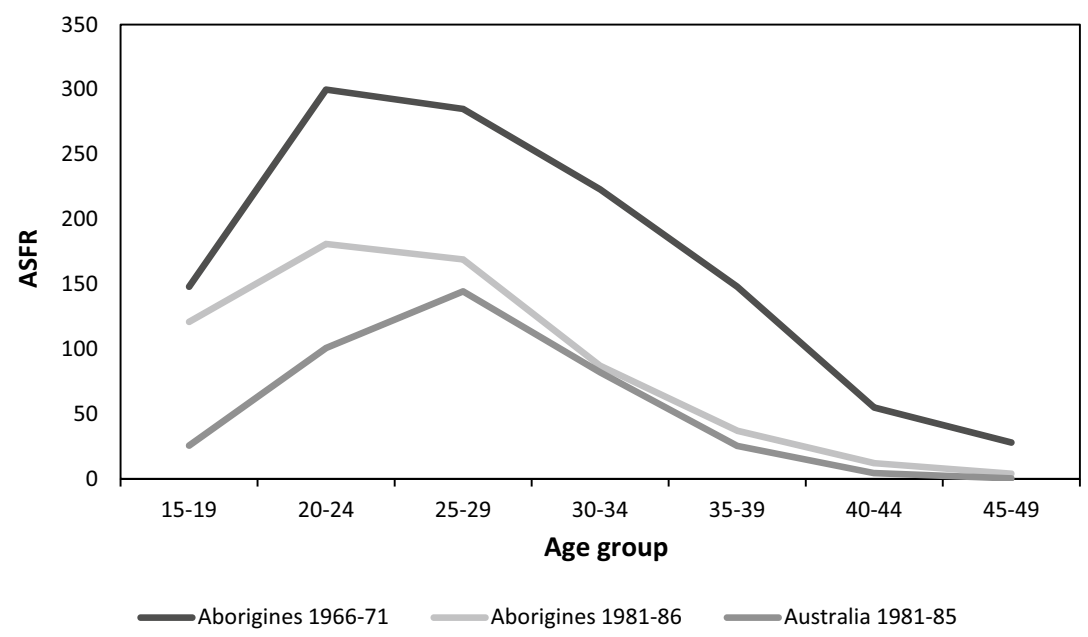

Fig. 1 Age-specific fertility rates, Aborigines 1966-1971 and 1981-1986 and Australia 1981-1985

aged 0-14 with their mothers within households (own children), classifies them by age and mother's age, then (after making any adjustments for census undercount and/or age misreporting) reverse-survives them and adjusts their mothers' ages to their birth years to obtain numbers of births by age of mother for the 15 years preceding the census. Non-own children (those without identifiable mothers in their households) are then similarly treated and added in, assuming that, for children of a given age, mothers have the same age distribution as mothers of similarly aged own children. All women aged 15-64 are then also reverse-survived to estimate total women aged 15-49 by age for the 15 years preceding the census, and reverse-survived births for maternal age groups are divided by reverse-survived total women in those age groups to yield annual age-specific fertility rates, and by extension total fertility rates, across the 15 year period.

Jain's (1989) analysis, of necessity, made assumptions and approximations to deal with difficulties matching children with mothers and the need to exclude children with Aboriginal fathers but non-Aboriginal mothers. He eventually produced two sets of age-specific and total fertility rates for 1971-1986, calculated for 2-year and 5-year periods. The latter estimates stood direct comparison with Gray's estimates for 1971-1976, 1976-1981 and 1981-1986, and reassuringly TFRs matched quite closely. However as Gray (1990) pointed out, Jain's age-specific fertility rates were distinctly lower than his at younger ages and higher at older ages. Moreover, his TFRs for 2-year periods plus 1985-1986 showed a curious 17\% decline from 1981-1983 to 1985-1986. The former anomaly reflected the unusually high proportion of Aboriginal children who were 'non-own' children, given by Jain (1989) as $24.6 \%$ and $30.3 \%$ under his two analytic scenarios. The likely source of such high figures was the common occurrence of Aboriginal children, especially those of younger mothers, residing with other relatives. This was likely to have seen some children wrongly matched to women who were not their mothers and were older 
than their mothers. Furthermore, because non-own children were likely disproportionately to be the children of younger mothers, ascribing those of different ages the maternal age distributions of same-aged own children was likely to have assigned them distributions older than they should have been. So maternal ages were on both counts biased upward. As to the supposed recent sharp decline in Aboriginal fertility, this was clearly a spurious product of well-known census under-enumeration of very young Aboriginal children that had not been corrected for. Age groups 0, 1 and 2 were the source of births for immediate pre-census years under the own children method, which for all that it required only data from a single census, thereby eliminating problems of non-comparability between censuses, clearly had serious limitations in application to the Aboriginal population.

Once children-ever-borne data from the 1996 Census became available, Gray (1997) was able to update his fertility rates to embrace the 1986-1996 intercensal period (Table 2). A further 9\% decline in the all-Australia TFR compared to 1981-1986 was revealed, most of it concentrated in the 25-29 age group and only a little attributable to younger ages. Further TFR declines were recorded for other urban and rural areas (7\% and a substantial 19\% respectively), plus a reversion to decline (by almost 5\%) for major urban areas. In all three areas the major declines occurred at ages 25-29, but the more substantial rural decline did also feature reasonably large decreases at ages 20-24 (from 197 to 178 per 1000) and 15-19 (from 141 to 130 per 1000), and big drops at older ages (from 88 to 69,32 to 16,8 to 1 and 8 to 1 per 1000 at ages $30-34$ to $45-49$ respectively). The 1986-1996 rural TFR roughly equalled the major urban figure, a massive change from the pre-transition situation when in 1966-1971 it was nearly 50\% higher. Other urban fertility was now the highest, around $15 \%$ above that for major urban areas.

As an aside it should be noted in passing that more recently Zhang (2014: Fig. 4.1) has produced single-year own children TFRs for Indigenous women for 15-year periods prior to each census from 1991 to 2011. This exercise yielded trend lines based on censuses five years apart (e.g., 2006 and 2011) and 10 years apart (e.g., 2001 and 2011) that overlapped for 10 years and five years respectively. A consistent pattern emerged across the 20-year period 1991-2011. Overlapping fertility estimates from different censuses were very similar, except for the five years immediately preceding a census, when they were decisive under-estimates compared to what the subsequent two censuses showed for the same period. Zhang dubbed this a 'catch up effect', arguing that it could not plausibly be attributed to age misreporting or large-scale undercounting of both mothers and their children. Instead the 'only reasonable explanation' ( $p$ 16) was that significant numbers of both children aged $0-4$ and their mothers were not identified as Indigenous at any given census but were identified five and then 10 years later once the children were aged 5-9 then 10-14. This was a major component of the identification change widely held to have dramatically boosted Indigenous population growth over recent decades. 


\section{Updating Alan Gray}

\section{Technical matters}

Alan Gray's passing in 2001 was a massive loss to Australian Indigenous demography. In updating his fertility estimates for 1996-2006, 2006-2011 and 2011-2016 his methodology has by and large been faithfully replicated. Fortunately, all more recent censuses that have asked a children-ever-borne question have asked all women about all children, so there was no need to engage in complex data adjustment such as Gray undertook. It is, however, desirable at this juncture to present some technical detail to be absolutely clear as to what has been done.

The Australian Bureau of Statistics maintained its policy of collecting children-ever-borne data only decennially after 1996, so that again no data are available from the 2001 Census. Thankfully the policy was abandoned following the 2006 Census, so these updates are based on CEB data for 1996, 2006, 2011 and 2016. Tables showing for Indigenous women (those of Aboriginal and/or Torres Strait Islander origin) children-ever-borne by 5-year age groups and whether resident in major urban, other urban or rural areas were extracted for 2006, 2011 and 2016 using the Australian Bureau of Statistics' Tablebuilder facility. As noted earlier, geographic comparability with Gray's analyses was maintained by continuing to treat Darwin as an 'other urban' area rather than a 'major urban' area in 2011 and 2016. Data for 1996, not accessible via Tablebuilder, were kindly provided by the ABS.

CEB data were available by single-child categories 0 to 6+for 1996 and 2006, and 0 to $8+$ for 2011 and 2016. For 1996 and 2006 the $6+$ category was split into 6 , 7 and $8+$ categories assuming that, for a given 5-year age group, the proportionate distribution across these categories for 2011 and 2016 combined prevailed. When then calculating age-specific mean parities, women with $8+$ children were assumed to have an average of 9 children. Gray in his calculations dealt with parity categories truncated variously at $8+(1966$ and 1981), 10+(1971) and $12+(1976)$. He, too, adopted the principle of splitting categories truncated at lower levels into more refined categories based on more detailed categorizations at another census (in his case 1976), and assumed that $12+$ children meant an average of 13 children. The approach taken here is similar, but it was decided not to adopt more detailed 1971 or 1976 distributions as they reflect a time when Indigenous fertility was a lot higher, and extremely high parities were almost certainly much more common than they are likely to have been around and after the turn of the millennium.

A well-known issue with CEB data is an inclination of respondents to often not answer the question when the appropriate answer is in fact zero. The so-called 'zero error' arises when respondents, or enumerators on their behalf, either perceive the CEB question to be not relevant or deem leaving it blank equivalent to answering ' 0 '. It is a particular problem at ages 15-19, where parents or other adults answering on behalf of teenage daughters/young women, or young women themselves, may deem the CEB question irrelevant, inappropriate or even offensive, and ignore it. But older women who have perhaps never had relationships and parents or others answering on their behalf can have similar reactions, and persons of any age 
are at risk of assuming that leaving the answer blank is equivalent to a response of ' 0 '. If CEB data are processed simply ignoring 'Not stated' cases or assuming that they follow the parity distribution for women of stated parity the outcomes are equivalent, and mean parity is likely to be overestimated. To deal with this issue El Badry (1961) developed a method for splitting CEB 'not stated' cases into those that were in reality zero parity and those genuinely not stated. It was modified by Gray (1983a: Appendix 1), and his modified approach was adopted here to estimate zero errors and adjust parity distributions before mean parities by age were computed. As a guide to adjustments made, across the four census dates and three place of residence categories (i.e., 12 calculations) the median adjustment made at ages 15-19 transferred $66.0 \%$ of parity not stated cases to parity 0 . At ages 25-29 the median was $30.5 \%$. Following these adjustments, age-specific mean parities were calculated as the basic input into Zlotnik and Hill's (1981) procedure for estimating intercensal fertility rates.

This procedure basically takes census age-specific mean parities then focuses on cohort changes in mean parity from one census to the next. It is assumed that one is dealing with the same women at successive censuses and that they respond to CEB questions with equal (and ideally complete) accuracy on each occasion, whence a cohort's mean parity only ever increases as it ages and only positive cohort increments are encountered. Unfortunately, things don't always work out so neatly. One is not dealing with exactly the same women at each census, those that do remain in the population across censuses don't necessarily respond consistently over time, and negative cohort increments can be encountered. These, when they occur, typically do so between ages 40-44 and 50-54 (ignoring older age groups irrelevant to the Zlotnik/Hill methodology)_ages where relatively little childbearing occurs so that cohort increments are expected to be positive, but small. Gray encountered such negative increments and responded by setting them equal to zero, 'since most or all of such [parity] decreases can be attributed to misstatement of parity by older mothers' (Gray 1983a: 82). It is certainly plausible that some older mothers might understate their parities by excluding children who had died, left home or become estranged, and in doing so lower their cohort's mean parity. However, with Australia's Indigenous population other phenomena cannot be overlooked-intercensal improvement in Indigenous census coverage and intercensal identification change (to 'Indigenous' from either 'non-Indigenous', or 'Indigenous origin not stateditem non-response'). Item non-response refers to failure to answer a question in the course of otherwise (mostly) completing a census questionnaire. Such 'not stated' codings tend, however, in Australian censuses to be a minority of all 'not stated' codings. Most of these, $73 \%$ at the 2011 Census, are associated with records imputed in their entirety to represent persons either suspected of residing in private dwellings for which no questionnaire was returned, or known (from a list of residents) to live in a non-private dwelling but failing to return a personal questionnaire. Residents temporarily overseas (RTOs) also affect Indigenous population composition, disappearing or rejoining between one census and the next.

Varying but not infrequently substantial 'errors of closure' have been associated with successive Indigenous population counts since the 1971 Australian Census (O'Donnell and Raymer 2015), the date from which issues of census undercount etc. 
began to receive serious ABS attention. An 'error of closure' is the residual element of intercensal population increase still unaccounted for after subtracting net increase attributable to demographic processes (fertility, mortality and migration). So, for example, for the 1991-1996 intercensal period the error of closure in an Indigenous population increment of 87,600 was estimated to be 44,400 , or $12.6 \%$ of the 1996 count (Ross 1999); for 2006-2011 the Indigenous count increase of 93,300 incorporated an estimated error of closure of 27,800 , or $5.1 \%$ of the 2011 count (Australian Bureau of Statistics 2013); and for 2011-2016 the Indigenous count increment of 100,800 included an error of closure of 21,500 , or $3.3 \%$ of the 2016 count (Australian Bureau of Statistics 2018). It is sometimes assumed errors of closure derive exclusively from identification change, but improvements in census coverage (reduced undercount) and processing can also contribute, as can inaccuracies in the fertility, mortality and migration estimates used to measure the demographic component of change. Improvements in coverage and processing are not, however, easy to measure, nor are their likely impacts in boosting or lowering cohort fertility clearcut. Concerted efforts, supported by additional funding, were, for instance, made to improve procedures for counting Indigenous Australians between the 2006 and 2011 Censuses (Australian Bureau of Statistics 2012), but while higher data quality and better coverage were thought to have resulted, they could not be quantified.

Identification change has been a much discussed source of intercensal Indigenous population growth for some time now (Zhang 2014). Recently Biddle and Markham (2018) used the Australian Census Longitudinal Dataset (ACLD) to add substance to this discussion. The first ACLD iteration (2006-2011) linked a 5\% sample of 2006 Census records with matched 2011 records while the second (2011-2016) links $5.7 \%$ of 2011 records with matched 2016 records. Accurate measurement of identification change requires longitudinal data at two points in time such as these datasets provide. Analysing the 2011-2016 data Biddle and Markham defined four groups-those who always identified as Indigenous (in both 2011 and 2016), those who never identified (at either date), those who newly identified (in 2016, but not 2011) and those who formerly identified (in 2011, but not 2016). This classification excludes persons born or dying in, or migrating to or from Australia between the two censuses, or temporarily overseas at either census. By far the largest group had 'never identified' (estimated at 20.3 million weighted up to national level), followed by the 'always identified' group (572,000). Some 45,000 'formerly identified' and almost 130,000 'newly identified' in 2016, a net increase from identification change of nearly 85,000 , or $13.7 \%$ of the combined 'always' and 'formerly' groups as of 2011. Some uncertainty surrounds these figures in that the ABS's linking process cannot be considered entirely error-proof, but classifications as 'formerly identified' attract more doubt than those as 'newly identified', suggesting that, if anything, net identification change might have been under-estimated. It did, in any case, exceed Biddle and Markham's estimate of intercensal Indigenous natural increase, just over 79,000 .

Net identification change was highest $(17.1 \%$ ) at ages $0-14$, but was also in the range 11-14\% across ages between 15-24 and 45-54 (Biddle and Markham 2018: Fig. 3, data unrefined by sex), suggesting not insubstantial boosting of the 
self-identified Indigenous population across the female reproductive age range as well. Net identification change was, moreover, far lower in the Northern Territory (1.8\%) and Western Australia (6.5\%), where remote Indigenous communities are mainly located and relatively low proportions of registered Indigenous births during 2001-2016 were to non-Indigenous mothers by Indigenous fathers, than in Victoria (21.5\%), the ACT (20.9\%) and New South Wales (20.8\%), where many Indigenous people live in major cities and interpartnering is far more common. Combining these realities there seems every likelihood that women of reproductive age transferring between censuses from the non-Indigenous to the Indigenous population might have tended to be more non-Indigenous than Indigenous in their fertility behaviour, and so had lower average fertility than the Indigenous cohorts they augmented. At more reproductively active ages (15-39) this, in an analysis such as the present one, will have manifested as Indigenous fertility decline. At older reproductive ages (40-49) there is obvious scope for it to have contributed, perhaps along with underreporting of parity of the type invoked by Gray, to negative cohort increments in mean parity. Indeed, it would not be surprising if it was the main responsible factor.

It was noted above that Gray's response to negative cohort mean parity increments was to set them equal to zero. That approach was found to be unsatisfactory here, triggering a departure from strict compliance with Gray's methodology. It contributed later in calculations, where cumulative mean CEB to exact ages 20, 25, $30,35,40,45$ and 50 were obtained, to situations where negative increments were obtained between exact ages 40 and 45 or 45 and 50, implying negative age-specific fertility rates, a nonsense. It was concluded that negative cohort mean parity increments needed to be replaced not with zero increments, but with small positive ones. It was therefore decided to assume, where a negative cohort mean parity increment occurred, that it should be replaced by a positive increment proportionately the same as that for the most immediately adjacent, but earlier, equivalent positive increment. To effect these adjustments where they modified a 2006 Census age-specific mean parity, a set of 2001 age-specific mean parities was created which were means of equivalent 1996 and 2006 mean parities. Thus if, for example, the mean parity transition from age group 40-44 in 2006 to $45-49$ in 2011 was negative, the positive transition from age group 40-44 in 2001 to $45-49$ in 2006 was used to determine a replacement mean parity at ages 45-49 in 2011 - one that was greater than the 2006 mean parity at ages $40-44$ by the same proportion as the 2006 mean parity at ages 45-49 exceeded the 2001 mean parity at ages $40-44$. Arbitrary as it was, this procedure eliminated negative increments in cumulative mean CEB. Its use means that age-specific fertility rates at ages 40-44 and 45-49 in Table 2 should be taken with a grain of salt, as is fairly obvious from inspecting them, and as probably applies in respect of Gray's pre-1996 calculations in Table 2 as well. They are, however, minor contributors to TFR estimates; the important changes are the ones that occur at younger ages where most childbearing takes place. 


\section{Results}

Refocusing on Table 2, the updated results occupy the righthand three columns. Various graphs derived from this table follow, which confirm visually observations previously made concerning the fertility decline of the 1970s. For the total Indigenous population Table 2 indicates continued decline in the TFR between 1986-1996 and 1996-2006, stability to 2006-2011, then substantial further decline to 2011-2016 (Fig. 2). The period of stability represents a cancelling between fertility decline at ages 15-19 and 20-24, and increase at ages 25-29, 30-34 and 35-39 (Fig. 3). While some fertility decline had begun at ages 15-19 after 1976-1981, it accelerated after 1986-1996, the age-specific fertility rate more than halving between then and 2011-2016 (Table 2, Fig. 3). Clearly teenaged childbearing, so resistant to change during the initial fertility transition, has lately become less a feature of Indigenous family formation, accounting for $12.6 \%$ of total fertility in 2011-2016 compared to $21.8 \%$ in 1976-1981. To what extent this decline might be attributable to an increased focus on education, reduced coital activity or greater fertility control are matters for conjecture. It may also to a degree reflect identification change having diluted adherence to Indigenous family formation norms by adding to the Indigenous population individuals who, although now claiming Indigenous origin, nonetheless do so embracing essentially non-Indigenous family formation ideals. Such a proposition is consistent with findings of Biddle and Markham (2018) that identification change during 2011-2016 was concentrated geographically (a) in urban places, especially major cities, and (b) in States (most notably New South Wales and Victoria) where proportions of Indigenous births occurring to non-Indigenous mothers, a proxy for the prevalence of Indigenous/non-Indigenous interpartnering, were well above the national average. Despite this, the importance of teenage childbearing to Indigenous total fertility still greatly exceeds its importance to overall total fertility. The latter averaged just 3.1\% across calendar years 2011-2016, compared to the $12.6 \%$ Indigenous figure quoted above.

At ages 20-24 a downward trajectory under way for the total Indigenous population since the early 1960s (Table 2, Fig. 3) continued across the updates added here, accelerating anew between 2006-2011 and 2011-2016 when modest upward trends at ages 25-29, 30-34 and 35-39 between 1986-1996 and 2006-2011 also reversed. Overall stability between 1996-2006 and 2006-2011 was matched by the rural Indigenous population (Fig. 4), again with declining fertility below age 25 being offset by rising rates at ages 25-29 and 30-34, but not 35-39 (Table 2). Substantial rural decline across all ages below 40 years then occurred from 2006-2011 to 2011-2016, the rural TFR falling sharply from 2.68 to 1.89 , lower than for either of the two urban geographic categories (Fig. 4). This was after 1986-1996 to 1996-2006 had seen a slight increase in rural Indigenous fertility. Major cities and other urban areas both also recorded significant 2006-2011 to 2011-2016 fertility declines, respectively building on a modest decline and reversing a modest increase between 1996-2006 and 2006-2011.

Notable from Fig. 4 is the contrast between the pre-fertility transition period, when Indigenous fertility levels for major urban, other urban and rural areas were 


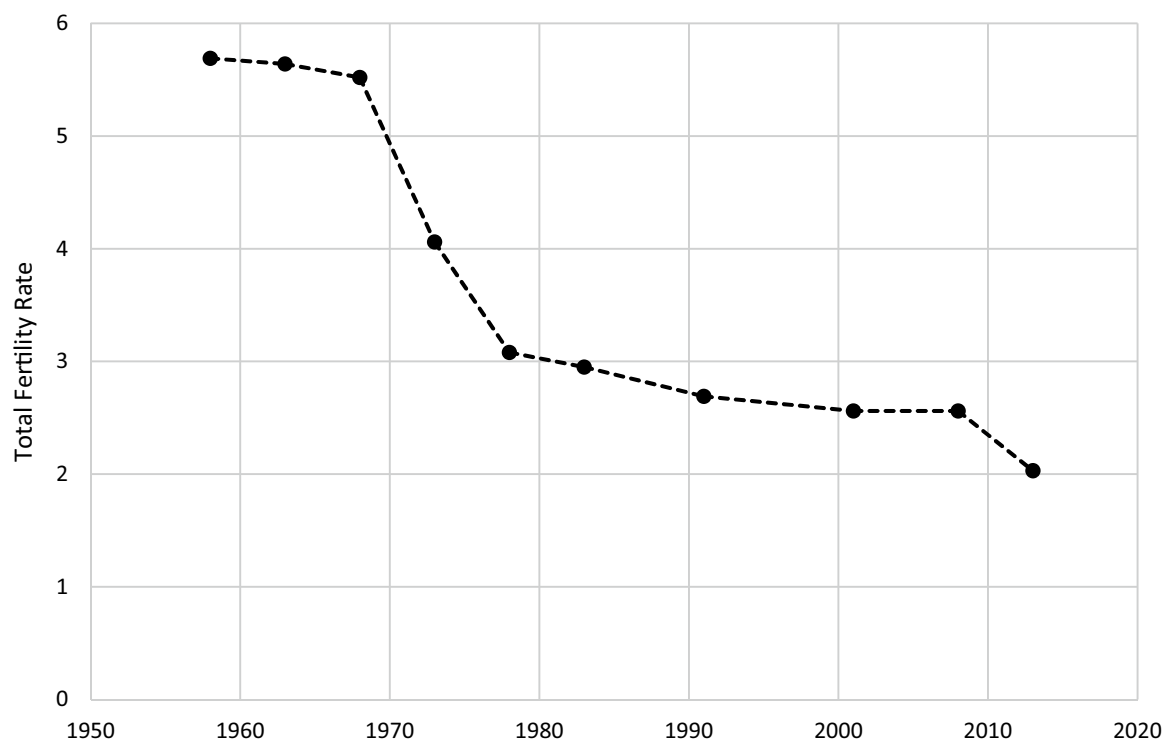

Fig. 2 Indigenous total fertility rates 1956-1961 to 2011-2016

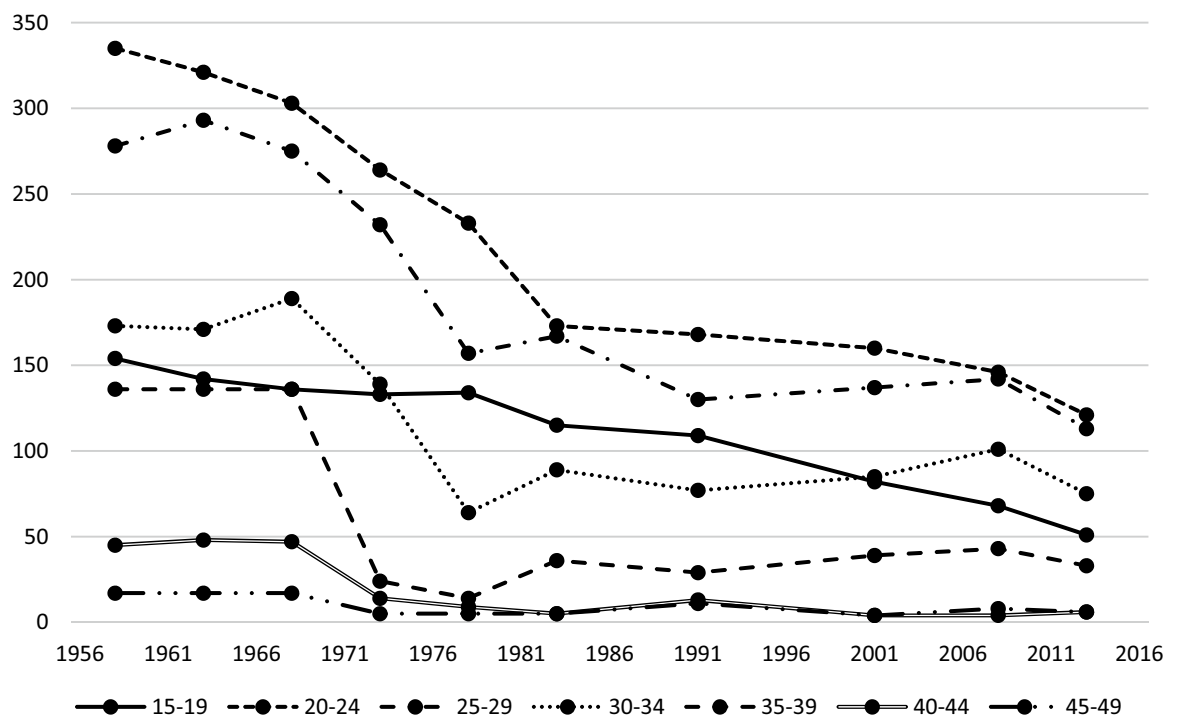

Fig. 3 Indigenous total age-specific fertility rates 1956-1961 to 2011-2016

quite different (save for 1966-1971 when other urban and rural TFRs were near identical), and the more recent post-transition period when there has been far less disparity. As already noted, the transition itself was initially (1966-1971 to 1971-1976) focused on other urban and rural areas, so that differentials by residential location 


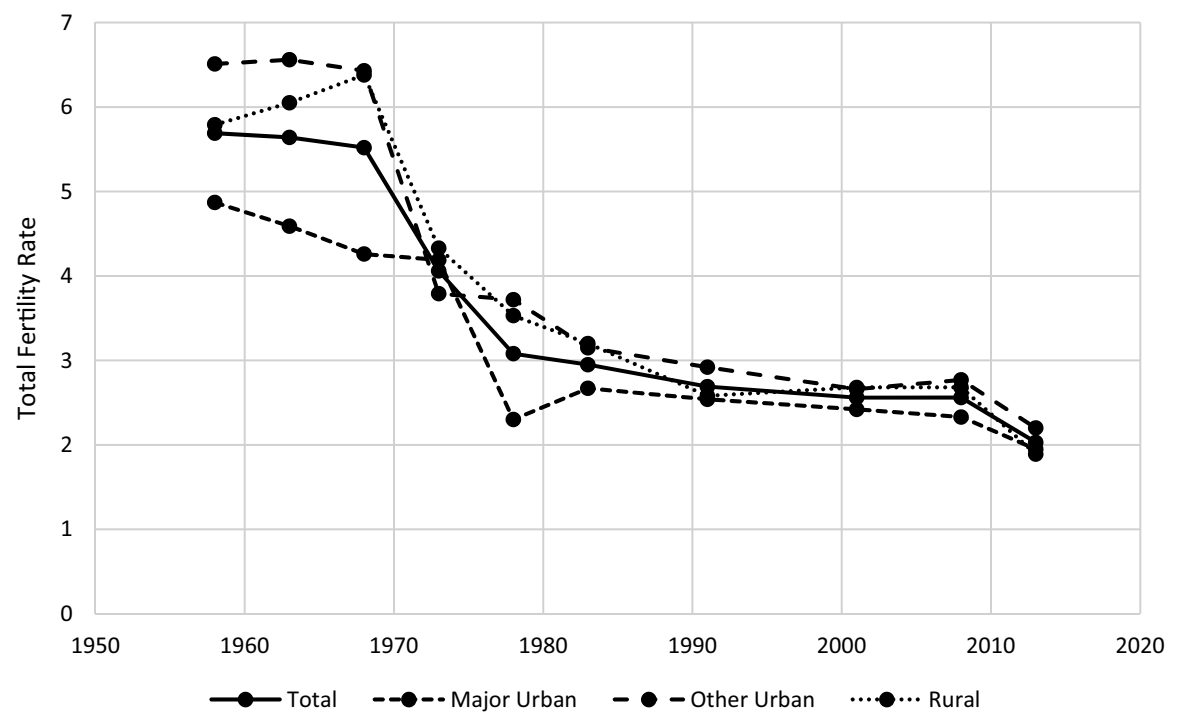

Fig. 4 Indigenous TFRs by residential location 1956-1961 to 2011-2016

had been substantially reduced by 1971-1976, but there then followed a catch-up to 1976-1981 during which sharp fertility decline in major urban areas re-established distinctly lower fertility in larger cities. Almost certainly this pattern reflected an initial rural and regional focus of the Aboriginal health initiatives to which Gray (1983a) attributed the transition. Post-transition Indigenous fertility has for the most part continued to be lowest in major urban areas, but by substantially reduced margins in both absolute and proportionate terms.

Figure 5 shows age-specific fertility rates for the three residential location categories. The graph for age group 15-19 shows that until quite recently when the rural and other urban rates converged, teenage fertility was consistently highest in rural areas and somewhat lower in other urban areas, with the major urban rate always, and still, appreciably lower than either of the other two. Larger cities provide Indigenous youth a wider range of lifestyle (including educational, career and social experience) options than smaller urban and rural areas do, and perhaps foster less strict compliance with traditional family formation patterns than in areas where residence in discrete Indigenous communities is more common and interpartnering, with its potential for causing non-Indigenous values to intrude on couple decisionmaking, is less so. At ages 20-24 the pattern is a bit different. Until halfway through the 1970 s fertility transition, fertility at these ages was lowest in rural areas, probably because women were so much more likely to have commenced childbearing in their teens. After mid-transition, however, major urban women again consistently recorded the lowest fertility, as rural women tracked more towards the trajectory for other urban women, who throughout, with a minor exception in 1981-1986, had the highest fertility at these ages.

At ages 25-29 other urban fertility was clearly the highest pre-transition, became very similar to that in rural areas during the transition, and more recently has again 
Ages 15-19
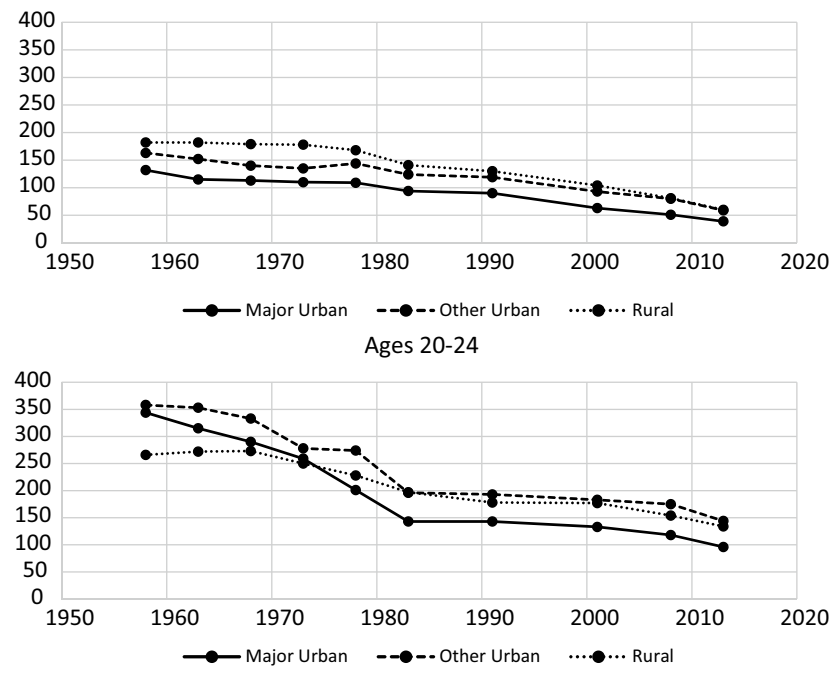

Ages 25-29

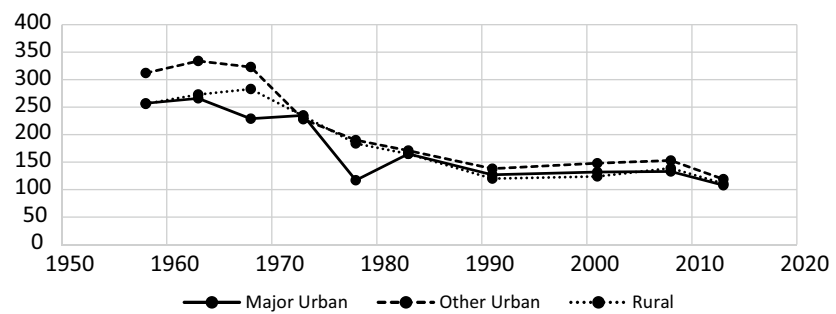

Ages 30-34

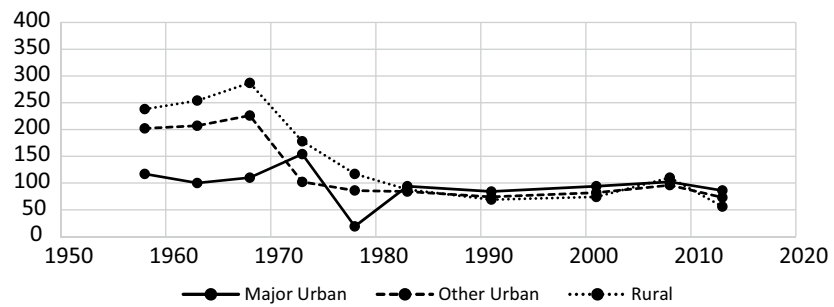

Ages 35-39

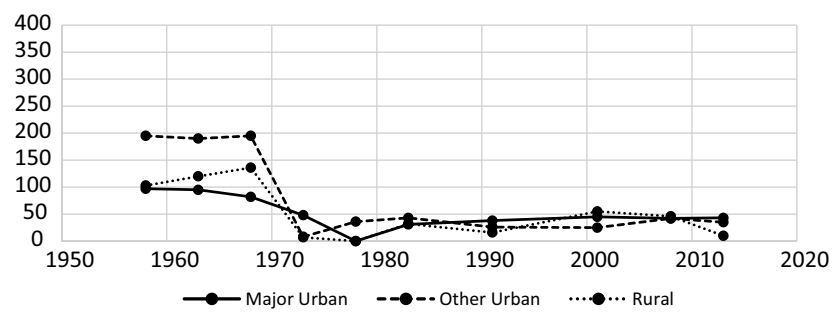

Fig. 5 Indigenous ASFRs by residential location 1956-1961 to 2011-2016 
been the highest, but by more modest margins (Fig. 5). Since 1981-1986, rural and major urban fertility levels at these ages have consistently differed little. Ages 25-29 and 30-34 were primarily responsible for the noticeable dip then recovery in the major urban TFR between 1971-1976 and 1981-1986 (Figs. 4 and 5). Seemingly some of the fertility decline at these ages as major cities belatedly joined in the fertility transition (1971-1976 to 1976-1981) was offset (1976-1981 to 1981-1986) as reductions at younger ages fed through to render these more normative ages for lower parity childbearing. Essentially higher parity births were first averted, then partially replaced by lower parity ones as deferred childbearing at younger ages fed through. A final point to note from Fig. 5 is that the pre-transition geographic disparity in TFRs (Fig. 4) was substantially attributable to disparities at ages 30-34 and $35-39$.

\section{Fertility rates based on birth registration data}

From the late 1980s the Australian Bureau of Statistics began publishing Indigenous fertility rates (i.e., fertility rates for Indigenous women, excluding births to non-Indigenous women by Indigenous fathers) based on birth registration data. It is of interest to examine how these have compared to rates derived from census CEB data. Initially rates were published for States/Territories for which registration was assessed to be at least $90 \%$ complete. Thus, TFRs were published for the Northern Territory and South Australia from 1988, Western Australia from 1993, Queensland from 1997, and New South Wales and Victoria from 1998. AllAustralia figures were published annually from 1998, but it then became apparent from a graph in Births Australia 2000 that estimates also existed for 1996 (the year Queensland first produced registration data on Indigenous births) and 1997. The latter figure was also published in Births Australia 2000; that for 1996 was obtained from unpublished ABS records. Tasmanian figures began in 1999, and there was also an isolated New South Wales TFR published for 1995, three years before annual rates for that State began. Navigating published registrationbased Indigenous TFRs is, however, something of a nightmare. For several reasons there have not been single series published nationally and by State/Territory.

First, as succeeding censuses have recorded Indigenous population growth well above demographic expectation, age-specific fertility rates for previous years have been rebased and hence TFRs revised, leading to overlapping series of different TFRs in different publications, the more recently based tending to be lower than those based to earlier censuses. Second, numerators, too, have been subject to change. Thus, Births Australia 2011 announced the detection of a 'systems processing error', correction of which had added 5179 records to the New South Wales birth count for that year, including 1215 (23.5\%) that pertained to Indigenous births. The number that were births to Indigenous mothers was not disclosed in the relevant 'Technical Note', but the error was later confirmed to date from 2005, and for 2005-2010 counts of births to Indigenous mothers were revised up by between 503 (2005) and 1051 (2010), or on average 775 births per annum. Along similar lines the Queensland Registry in 2009 implemented 
a 'Retrospective Births Project', in which 1780 birth registrations with hitherto incomplete information were finalized and statistically reported in a concerted clean-up. It was estimated that about 40\% (around 700) of these were Indigenous births, although once again no indication was given of the proportion that were births to Indigenous mothers.

Queensland's clean-up highlighted an important imprecision in Indigenous birth registration data (see also Zhang 2014). It is normal for there to be a lag between occurrence of a birth and its registration. It takes time for parents or other 'responsible persons' to register a birth (legally they have 60 days, except in Western Australia (1 month) and Tasmania (21 days)), and additionally the lag can be influenced by processing delays within birth registries, whose protocols governing when dates of registration are assigned vary by State/Territory. The evidence is, however, that delays in registering Indigenous births are on average appreciably longer than those in registering births in general. Thus, as fertility data typically are tabulated by year of registration, not occurrence, Indigenous fertility data are less up-to-date than fertility data in general, and apt to include sizeable catch-up elements of late-registered births that actually occurred many months and even years earlier.

The ABS has demonstrated this differential in two ways. In Births Australia for the years 2007-2010 it published, by State/Territory for 6-month periods across 2004-2010, average intervals between occurrence and registration of all and Indigenous registered births. For all births the Australian average over the fourteen halfyears was 2.41 months; it was 7.52 months for Indigenous births, over three times as long. There was also considerable variation by State/Territory. For the Northern Territory, with easily the highest proportion of total population Indigenous, respective averages were ironically just 1.12 months and 1.56 months. This reflected a practice of registering births on a preliminary basis using notifications from maternity hospitals if not parentally registered within 60 days, then adding details such as the child's name and the father's particulars once parentally registered. Tasmania, with a similar preliminary registration system and a requirement to register within 21 days, also recorded relatively low average lags between occurrence and registration. At the other extreme, however, averages were 2.41 months (overall) and 10.65 months (Indigenous) for Western Australia, and 3.95 months and 11.53 months for Queensland (registration delays exceeding 72 months assumed in these calculations to be of exactly 72 months, to limit outlier influence). More recently ABS practice has been to publish each year, by State/Territory, percentages of births registered that occurred during the year of registration. Annual averages for Australia during 2009-2016 were $86.6 \%$ for all births and $72.3 \%$ for Indigenous births, State/Territory extremes again provided by the Northern Territory (93.1 and $90.4 \%$ ), and by Western Australia (89.9 and 65.4\%) and Queensland (85.3 and 67.8\%). Moreover, non-trivial minorities of registered Indigenous births had occurred six or more years earlier-2009-2016 annual averages of 8.4\% for Australia, 9.1\% for South Australia, 10.0\% for Queensland and 14.9\% for Western Australia.

Other issues also affect the reliability of birth registration-based Indigenous fertility data. Births Australia documentation routinely cautions that not all Indigenous births are identified as such when registered, as Indigenous identification is not 


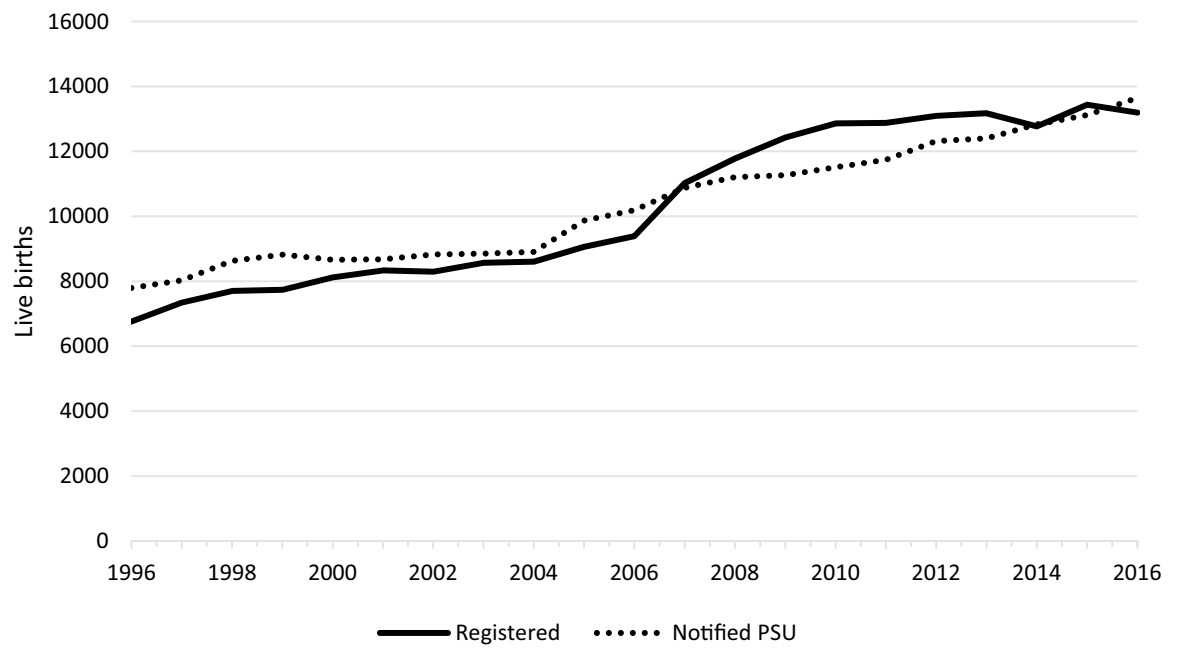

Fig. 6 Live births to indigenous mothers registered and notified to the perinatal statistics unit 1996-2016

consistent across the various bureaucratic forms individuals can be asked to fill out. It can vary with perceptions of how information on a particular form will be used, in response to education programs about Indigenous identification, as a function of whether the individual or someone else on their behalf actually completes the form, and in response to emotions Indigenous identification arouses. It is also of interest to compare registration data on live births to Indigenous mothers with similar data from the National Perinatal Data Collection of the Australian Institute of Health and Welfare (Fig. 6). The latter, tabulated on a year of occurrence basis, derive from midwives' reports on all births that take place in Australia. Only details of mothers and babies, not fathers, are reported, so 'Indigenous' live births are those that occur to Indigenous mothers. The evidence of Fig. 6 nationally is that during 1996-2006 registered live births to Indigenous mothers generally tracked a little (around 670 per annum on average) below Indigenous live births notified by midwives, suggesting under-registration at a level of around 7.6\% on average [Zhang (2014) produced a similar figure for the same decade]. Beyond 2006, however, trend lines cross, and the period 2008-2013 saw registered live births exceed notified live births by an average of 960 per annum, representing over $8 \%$ average over-registration. This is reflective of efforts made over that period by registries in a number of jurisdictions to clear backlogs of incomplete registrations, and of the consequent significant proportions of registrations that were of births that actually occurred years prior to the year of registration. More recently (2014-2016) the two Indigenous births measures have shown closer agreement, but it is as yet probably too early to pronounce the two data sources 'in synch'.

Table 3 summarises all-Australia Indigenous total fertility rate estimates published by the Australian Bureau of Statistics in annual Births Australia volumes between 1998 and 2016. Between 1998 and 2008 only a figure for the year in question was published. Those figures, together with the figures for 1996 and 1997 
Table 3 National indigenous TFR estimates published in Births Australia 1998-2016

\begin{tabular}{llllllllll}
\hline \multicolumn{7}{c}{ Published in Births Australia for } \\
\hline Year & Year in question ${ }^{+}$ & 2009 & 2010 & 2011 & 2012 & 2013 & 2014 & 2015 & 2016 \\
\hline 1996 & 2.024 & & & & & & & & \\
1997 & 2.113 & & & & & & & & \\
1998 & 2.151 & & & & & & & & \\
1999 & 2.133 & 2.091 & & & & & & & \\
2000 & 2.207 & 2.161 & 2.161 & & & & & & \\
2001 & 2.145 & 2.193 & 2.193 & 2.193 & & & & & \\
2002 & 2.193 & 2.154 & 2.154 & 2.154 & 2.154 & & & & \\
2003 & 2.145 & 2.191 & 2.191 & 2.191 & 2.191 & 2.191 & & & \\
2004 & 2.113 & 2.158 & 2.158 & 2.158 & 2.158 & 2.158 & 2.158 & & \\
2005 & 2.057 & 2.096 & 2.096 & 2.096 & 2.219 & 2.219 & 2.219 & 1.934 & 1.934 \\
2006 & 2.118 & 2.120 & 2.120 & 2.120 & 2.252 & 2.252 & 2.252 & 1.967 & 1.967 \\
2007 & 2.399 & 2.399 & 2.399 & 2.399 & 2.594 & 2.594 & 2.594 & 2.270 & 2.270 \\
2008 & 2.515 & 2.515 & 2.515 & 2.515 & 2.703 & 2.368 & $2.368 *$ & 2.368 & 2.368 \\
2009 & & 2.575 & 2.575 & 2.575 & 2.773 & 2.433 & $2.433^{*}$ & 2.433 & 2.433 \\
2010 & & & 2.575 & 2.575 & 2.801 & 2.459 & $2.459^{*}$ & 2.459 & 2.459 \\
2011 & & & & 2.740 & 2.740 & 2.408 & $2.408^{*}$ & 2.408 & 2.408 \\
2012 & & & & & 2.710 & 2.383 & 2.383 & 2.383 & 2.383 \\
2013 & & & & & & 2.344 & 2.344 & 2.344 & 2.344 \\
2014 & & & & & & & 2.222 & 2.222 & 2.222 \\
2015 & & & & & & & & 2.271 & 2.271 \\
2016 & & & & & & & & & \\
\hline
\end{tabular}

${ }^{+}$Except 1996 (obtained from ABS unpublished files) and 1997 (published Births Australia 2000)

*In Births Australia 2014 two different sets of Indigenous TFRs were published for 2008-2011 in different tables, these ones, which match figures published in adjacent years either side, and figures for the same years published in Births Australia 2012. The latter clearly were republished in error

Source: Australian Bureau of Statistics, Births Australia, annual volumes 1998-2016

obtained as previously described, appear in the column headed 'Year in question'. Then, from 2009, the practice began of publishing Indigenous TFR estimates for the year in question and ten preceding years (eleven preceding years in 2016). Various revisions are apparent in Table 3, most occurring when new censuses led to a rebasing of age-specific fertility rate denominators. This seems to explain changes between 'Year in question' figures and those published in Births Australia 2009. Not all were declines, but those that weren't do not reflect upward revisions of numbers of births to Indigenous mothers. Such upward revisions do, however, account for increases in 2005-2010 TFRs between 2011 and 2012. They are attributable to adjustments made following discovery of the 'systems processing error' in New South Wales data discussed above. TFRs for 2011 and 2012 took account of this error in their initial calculations. Then, between 2012 and 2013, TFRs for 2008-2012 were adjusted substantially down again as underlying age-specific 


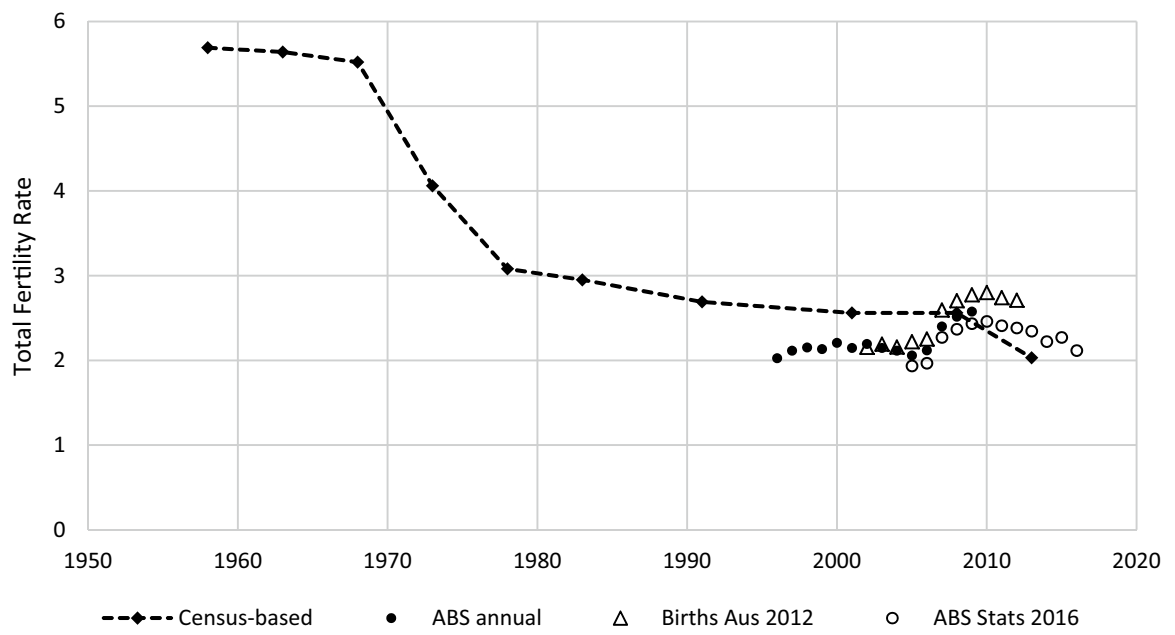

Fig. 7 Indigenous total fertility rates: census-based 1956-1961 to 2011-2016 and registration-based 1996-2016

fertility rates were rebased to 2011 census results. Four of these TFRs carry asterisks in the column of Table 3 corresponding to Births Australia 2014. An aberration occurred in this issue, two tables publishing different TFRs for 2008-2011. Those shown in Table 3, identical to the ones published the previous and following years, are clearly the 'correct' ones. The other set, presumably inadvertently, replicated figures published in Births Australia 2012. TFRs for 2005-2007 appear to have been rebased to the 2011 Census in Births Australia 2015.

Figure 7 replicates Fig. 2 but adds to the census-derived Indigenous TFRs three series based on registration data. The first, labelled 'ABS annual', consists of TFRs published in annual Births Australia volumes between 1998 and 2009. The second, labelled 'Births Aus 2012', is the series for 2002-2012 published in Births Australia 2012 after adjustment for the New South Wales 'systems processing error'. The third, labelled 'ABS Stats 2016', shows TFRs rebased to the 2011 Census for the period 2005-2016. Notably, where series overlap, the second series, except early on when the two are almost coincident, lies above the first, while the third series traces a lower trajectory than either of the other two.

The 'ABS annual' birth registration-based TFRs in Fig. 7 initially follow a steady trajectory more or less parallel to, but at a somewhat lower level than, the censusbased trend line between 1996 and 2005. A bit of an upward trend between 1996 and 1998 likely reflects declining under-registration as Queensland began identifying Indigenous births rather than any real fertility increase. 'ABS annual' TFRs then track upwards quite sharply to a level in 2009 very similar to the 2006-2011 censusbased TFR. The 'Births Aus 2012' trend line departs from a marginally lower level in 2002 but climbs more steeply to a distinctly higher one in 2009 and a peak in 2010, before heeling over and beginning to drop. This downward trend is continued to 2016 by the 'ABS Stats 2016' series, but this series tracks appreciably lower following rebasing to the 2011 Census. Compared to the census-based trend line the 
earlier registration-based trend is suggestive of significant under-registration. It is doubtful the sharp upturn after 2005 represents genuine fertility increase. It occurred as concerted efforts were being made to catch up backlogs of Indigenous births that had not been registered shortly after they occurred as legally required, causing registrations of births to Indigenous mothers to move rapidly from being fewer than births to Indigenous mothers notified by midwives to surpassing them in number (Fig. 6). A continuation of this catch-up process could also explain why the trend in registered Indigenous fertility since 2010 has been downward, as the census-based trend has been, but on a gentler gradient. It may have offset to a degree genuine fertility decline. Then again, an easing of catch-up registrations, hinted at by Fig. 6, may have created an illusion of fertility decline.

All in all, it is difficult to have much confidence in registration-based Indigenous fertility levels or trends. Widespread delays in registration of Indigenous births, and therefore almost certainly also of the roughly three-quarters that are births to Indigenous mothers, coupled with periodic clearing of backlogs of deferred registrations by birth registries have clearly adulterated registration data. And these are in any event undermined by the ongoing identification change attested to by successive census counts and uncertainty as to whether it has impacted numerators and denominators of age-specific Indigenous fertility rates equally. On the issue of registration delays there would seem to be a case for seeking to implement nationwide the sort of registration system that produces timely, if not necessarily initially fully detailed registrations in the Northern Territory. Dealing with the constant net migration from the non-Indigenous to the Indigenous census population and whether or not it is similarly boosting counts of births to Indigenous mothers over time is a more intractable problem. Two years after the 2016 Census one is currently bracing for a new series of Indigenous TFRs based to that census, which could be expected to lie distinctly below the 'ABS Stats 2016' series in Fig. 7.

Passing reference was made earlier to Zhang's (2014) own children fertility analyses using the 1991-2011 Censuses and his discovery of a pattern suggestive of appreciable under-identification of Indigenous children aged 0-4 and their mothers, but substantial rectification of this flaw by the time these cohorts are aged 5-9 then 10-14 at the following two censuses. Such a pattern does hint at likely significant under-identification as Indigenous in the birth registration process, but Zhang's interpretation of fertility trends formed by overlapping own children TFR estimates when cohorts are aged 5-14 and, together with their mothers, more completely identified at succeeding censuses is of interest. He writes (2014: 14) 'In the 1980s [the] TFR estimated from the 1991 Census was around 3 children per woman', then again (p 27) 'a reasonable estimate of the most likely scenario for fertility [is a] TFR of 2.7 children per woman during 1986-1996, 2.6 children during 1996-2006, and about 2.5 during 2006-2011.' These estimates are very close to those for equivalent periods in the final row of Table 2-gentle decline. The estimate for 2011-2016 in that table then points to acceleration of this decline. It will be fascinating to see if own children Indigenous fertility analyses of 2016 and later 2021 Census data yield evidence confirming such a development. A 2016 analysis was not undertaken for this paper because Zhang's work only came to notice via comments from an anonymous reviewer, to whom grateful acknowledgement is made. 
Ages 15-19 to 25-29

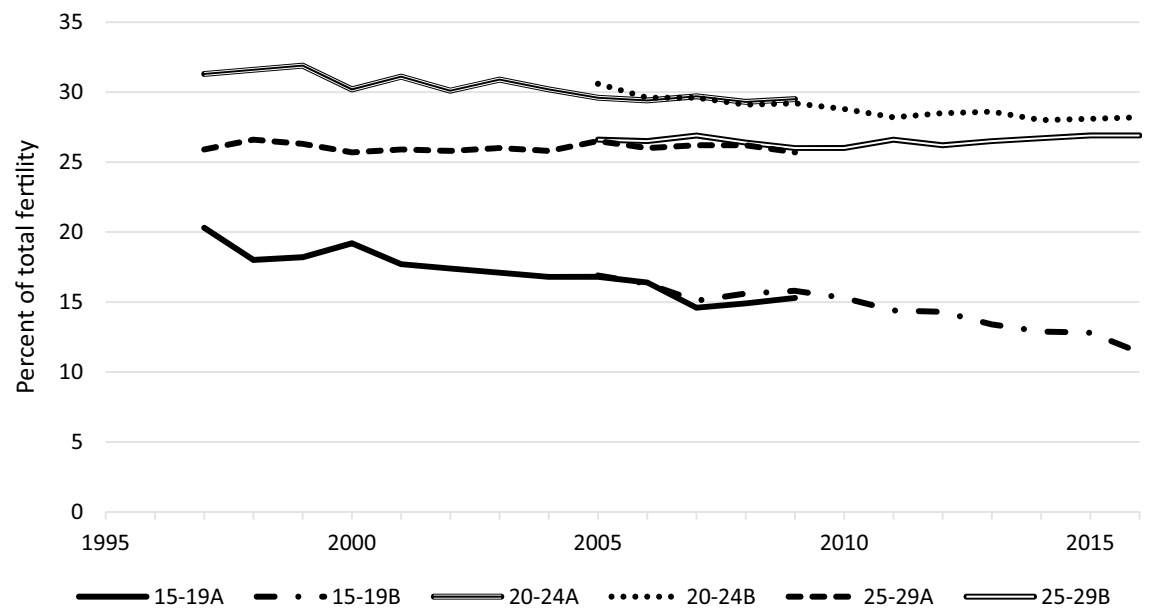

Ages $30-34$ to $40-44$

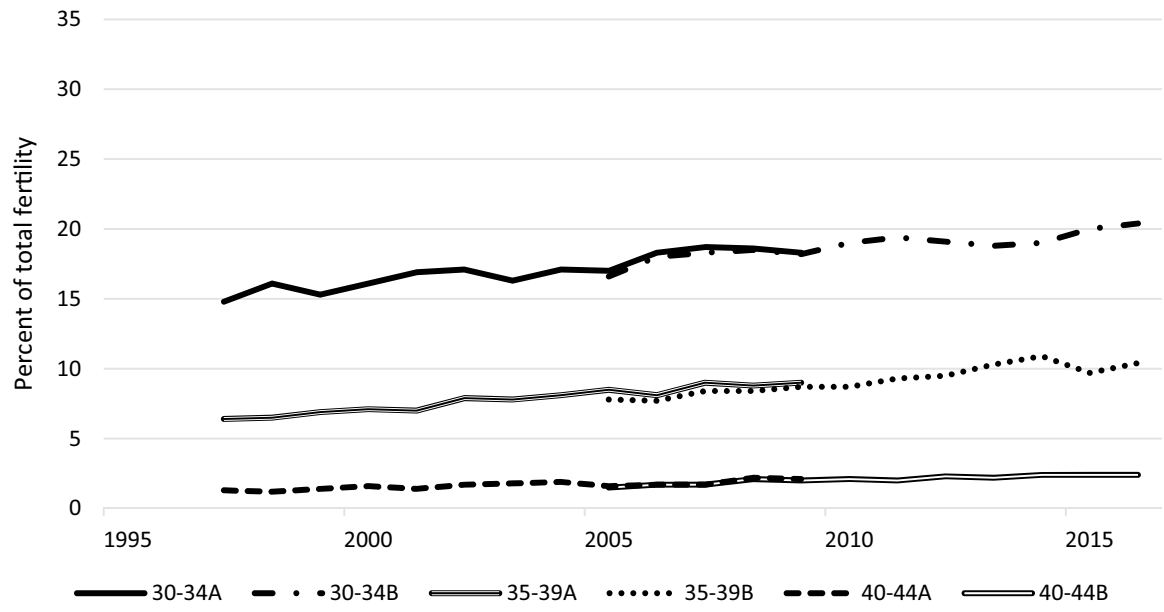

Fig. 8 Percentages of indigenous total fertility accounted for by 5-year age groups 1997-2016

One aspect of Indigenous fertility that may be more reliably captured by registration data is the changing age distribution of total fertility. In Fig. 8 are plotted percentages of total fertility as measured by the 'ABS annual' (Series A) and 'ABS Stats 2016' (Series B) data of Fig. 7 that are attributable to 5-year age groups 15-19 to 40-44. The two series overlap for the period 2005-2009, but trend lines for each age group are very similar across this portion of their trajectories. No Series A data for 1996 were available. The upper of the two graphs shows teenage fertility falling steadily from $20.3 \%$ of total fertility in 1997 to $11.4 \%$ in 2016 . Over the same period the equivalent overall fertility decline across Australia was from 5.5 
to $2.9 \%$, so despite the contribution of teenage fertility to Indigenous total fertility falling considerably it remains at a level almost four times that observed in the general population. A more modest decline is also evident in the contribution to Indigenous total fertility of the 20-24 age group, which from $31.9 \%$ in 1999 had dropped to $28.0 \%$ by 2014 (the overall decline over this period was from $16.8 \%$ to $13.3 \%$ ). A fairly constant $25-26 \%$ of Indigenous total fertility occurred at ages 25-29 over the period Fig. 8 covers. The increases to balance the declines at younger ages took place at ages 30-34 (from 14.8 to $20.4 \%$ between 1997 and 2016), 35-39 (from 6.4 to $10.4 \%$ ) and $40-44$ (from 1.3 to $2.4 \%$ ). Clearly the maternal age distribution of Indigenous fertility has been getting older, as has that of fertility in general, but Indigenous fertility remains appreciably younger. In 2016 almost $40 \%$ of Indigenous total fertility was births to women aged under 25 years, compared to a little over $15 \%$ of overall total fertility.

\section{Conclusion}

This paper set out to update census-based Indigenous fertility trends established by Gray (1983a) across quinquennia 1956-1961 to 1976-1981, then extended by him to cover 1981-1986 (Gray 1990) and 1986-1996 (Gray 1997), to embrace also the intervals 1996-2006, 2006-2011 and 2011-2016. In doing so it has also summarised and updated Gray's work on the longer term history of Aboriginal fertility and recounted his characterization of Aboriginal family formation as it had evolved by the 1960s from pre-contact times under European occupation. Alan Gray's passing in 2001 was an incalculable loss to Indigenous demography. Had he lived he almost certainly would have extended his own census-based trends. Instead, Indigenous fertility trends have latterly been monitored largely via birth registration data that, despite having become more readily available, remain in several respects problematic.

Gray's analyses were geographically refined to differentiate between residents of major urban, other urban and rural areas of Australia, as well as to provide results across all areas combined standardized to the distribution of Indigenous women by age and geographical location at the most recent census for which data were incorporated. Thus his original analysis standardized these rates to the 1981 distribution, subsequent updates restandardized them to 1986 then 1996 distributions, and this paper has restandardized them again to the 2016 distribution. Each restandardization altered the fine detail of 'total' results previously presented, but not their substance. Moreover, geographic comparability over time was maintained by continuing, in the update presented here, to treat Darwin as an 'other urban' area, despite it officially having become a 'major urban' area at the 2011 Census.

Indigenous fertility fell rapidly through the 1970s, by $44 \%$ between 1966-1971 and 1976-1981, predominantly at ages 30 and older where the decline was $76 \%$. It fell particularly steeply at ages 35 and older, where the bulk of the drop to 1976-1981 had already occurred by 1971-1976. There was also significant fertility decline at ages 20-29 over this period, but almost none at ages 15-19, 
affirming a strong and resilient emphasis in Aboriginal family formation on very high fertility among adolescent women. Concurrently there was also a sharp drop in infant mortality, the two trends jointly associated with a marked improvement in health services for mothers and babies. Geographically the fertility decline was initially (to 1971-1976) heavily focused on rural and other urban areas that were priority targeted by health service improvements. But during the following quinquennium declines in these areas slackened and that in major urban areas took off.

Further, more restrained fertility decline between 1976-1981 and 1981-1986 was rural and other urban-focused, decreases in these areas offset by a major urban resurgence. Across all geographic areas the reductions occurred at ages 20-24 (26\%) and 15-19 (14\%), the first indication that teenage fertility was moderating. Increments occurred at ages 25-29 to 35-39, but were not sustained to 1986-96, by which time overall Indigenous fertility had fallen a further $9 \%$ but rural Indigenous fertility by a more substantial additional 19\%. Overall decline was concentrated at ages 25-29, but the further rural decline was more spread by age, including across age groups 15-19 and 20-24 at which minimal urban change occurred. Thus by 1986-1996 a quite substantial 1981-1986 rural/major urban disparity in total fertility had almost disappeared, and 'other urban' fertility was now clearly the highest.

An important issue was raised in technical discussion associated with the updating of Gray's Indigenous fertility estimates to 1996-2006, 2006-2011 and 2011-2016. While the method Gray used assumed the composition of female cohorts remained unchanged from census to census and that women reported their fertility consistently (and ideally accurately) each time, the former assumption in particular was clearly invalid. Substantial errors of closure attached to Indigenous intercensal population increments over the period in question implied constant augmentation of cohorts in net terms, perhaps through improved census coverage but certainly through Indigenous identification change. This raised the issue of how women newly identifying as Indigenous compared with those who had consistently identified. The former seemed likely to on average have more marginal connections to Indigenous heritage in matters of family formation, to more often reside in major urban areas and have non-Indigenous partners, and therefore to more often embrace lower fertility non-Indigenous family formation ideals. Their inclusion would be expected to impart a downward bias to Indigenous fertility that at more normative ages for childbearing would manifest as fertility decline, but at older ones (40-44 and 45-49) might induce negative cohort fertility increments as this bias not only reduced typically small intercensal fertility increments, but eliminated them and then some.

The updated estimates indicated modest further overall fertility decline between 1986-1996 and 1996-2006, followed by no change to 2006-2011 then another more substantial drop to below replacement level in 2011-2016. Major urban fertility fell consistently, most sharply between 2006-2011 and 2011-2016; other urban fertility fell, rebounded slightly, then also declined most sharply to 2011-2016; and rural fertility initially increased slightly, remained stable to 2006-2011, but then dropped substantially to below even the level major urban areas recorded. Notably, though, 
geographic differentials in Indigenous fertility have since the early 1980 s been quite modest compared to what they were prior to the initial fertility transition.

By age the standout feature over the update period was the halving and more of the teenage fertility rate, which was replicated across all three geographic location categories. There were also consistent, and in net terms 1986-1996 to 2011-2016, significant reductions in fertility at ages 20-24 across all geographic categories, as overall the maternal age distribution of Indigenous childbearing became distinctly older. Teenage fertility has continued to be lowest in major urban areas, where the variety of lifestyle options is greater and arguably adherence to traditional family formation norms is moderated, but rural and other urban teenage fertility levels have latterly converged after the former previously was consistently higher. At ages 20-24, too, distinctly lower fertility in major urban areas has become established over the update period, with rural and other urban rates following similar, higher trajectories, although the latter have been marginally the highest. At older ages, 25-29 to 35-39, geographic differentials were marked and fluctuated over the pre-transition, transition and early post-transition phases, as higher parity births were eliminated then to a degree replaced by lower parity ones as initiation of childbearing was delayed and normative ages for lower parity births rose. Latterly, however, these differentials have become comparatively subdued.

Failure to update Gray's census-based work until now reflects efforts over the past two decades to improve Indigenous birth registration. Data derived therefrom are probably quite adequate for tracing trends such as the declining importance to Indigenous fertility of age groups 15-19 and 20-24. Unfortunately, however, in conjunction with constant redefinitions of age-specific Indigenous female risk populations as successive censuses have revealed large errors of closure, they do still leave much to be desired. Fertility levels change non-trivially when retrospectively rebased to more recent censuses or corrected for processing errors. And delays in registering Indigenous births, coupled with periodic registry efforts to clear backlogs of such births that often have spent years in limbo, create constant uncertainty as to whether movements in trend lines actually reflect contemporary change or are artefacts of registration system shortcomings. One initiative that might help would be for the system of preliminary registration from notifications provided by maternity hospitals of births not parentally registered on time that operates in the Northern Territory and Tasmania to be extended to all jurisdictions, since it appears to result in more comprehensive, timely capture of Indigenous births. There is, though, a potential problem in the lack of fathers' details in maternity hospital data, which would prejudice identification of Indigenous births to non-Indigenous mothers. These are not relevant to measuring Indigenous fertility (i.e., the fertility of Indigenous females), but they are important in monitoring Indigenous population growth, and are much more common in States with large metropolitan populations (e.g., New South Wales) than in the Northern Territory.

Open Access This article is distributed under the terms of the Creative Commons Attribution 4.0 International License (http://creativecommons.org/licenses/by/4.0/), which permits unrestricted use, distribution, and reproduction in any medium, provided you give appropriate credit to the original author(s) and the source, provide a link to the Creative Commons license, and indicate if changes were made. 


\section{References}

Australian Bureau of Statistics. (2012). Information paper: 2011 census special enumeration strategies, 2011. Catalogue 2911.0.55.004. Canberra: ABS.

Australian Bureau of Statistics. (2013). Census of population and housing: Understanding the Increase in Aboriginal and Torres Strait Islander Counts, 2006-2011. Catalogue 2077.0. Canberra: ABS.

Australian Bureau of Statistics. (2018). Census of population and housing: Understanding the Increase in Aboriginal and Torres Strait Islander Counts, 2011-2016. Catalogue 2077.0. Canberra: ABS.

Beasley, P. (1970). The Aboriginal household in Sydney. In R. Taft, J. L. M. Dawson \& P. Beasley (Eds.), Attitudes and social conditions. Aborigines in Australian society series (No. 2. pp. 131-189). Canberra: ANU Press.

Biddle, N., \& Markham, F. (2018). Indigenous identification change between 2011 and 2016: Evidence from the Australian longitudinal dataset. Topical Issue No. 1. Canberra: Australian National University Centre for Aboriginal Economic Policy Research.

Cho, L.-J., Retherford, R. D., \& Choe, M. K. (1986). The own-children method of fertility estimation. Honolulu: University of Hawaii Press.

Conor, L. (2016). Skin deep: Settler impressions of Aboriginal women. Perth: University of Western Australia Publishing.

Cowlishaw, G. (1978). Infanticide in Aboriginal Australia. Oceania,48(4), 262-283.

Cowlishaw, G. (1981). The determinants of fertility among Australian Aborigines. Mankind,13(1), 37-55.

Cowlishaw, G. (1982). Family planning: A post-contact problem. In J. Reid (Ed.), Body, land and spirit: Health and healing in Aboriginal society (pp. 31-48). St Lucia: University of Queensland Press.

Dugbaza, T. (1994). Recent trends and differentials in Aboriginal and Torres Strait Islander fertility: 1981-1991. Demography working paper 94/1. Canberra: Australian Bureau of Statistics.

Dugbaza, T. (1995). Some aspects of Aboriginal family structure and fertility. Aboriginal and Torres Strait Islander health information bulletin, 21, 39-47.

El Badry, M. A. (1961). Failure of enumerators to make entries of zero: Errors in recording childless cases in population censuses. Journal of the American Statistical Association,56(296), 909-924.

Gray, A. (1983a). Australian Aboriginal fertility in decline. Ph.D. thesis, Department of Demography, Australian National University.

Gray, A. (1983b). Aboriginal fertility at the time of European contact: The Daly River Mission baptismal register. Aboriginal History,7(1-2), 80-89.

Gray, A. (1984). Changes in Aboriginal family formation and fertility. In Family formation, structure, values. Proceedings of the Australian family research conference (pp. 380-408). Institute of Family Studies, Australian National University, 23-25 November 1983.

Gray, A. (1990). Aboriginal fertility: Trends and prospects. Journal of the Australian Population Association,7(1), 57-77.

Gray, A. (1997). The explosion of Aboriginality: Components of indigenous population growth 1991-96. CAEPR Discussion Paper 142. Canberra: ANU Centre for Aboriginal Economic Policy Research.

Jain, S. K. (1989). Estimation of Aboriginal fertility, 1971-1986: An application of the own children method of fertility estimation. Occasional Paper, Catalogue 4127.0. Canberra: Australian Bureau of Statistics.

Jones, F. L. (1963). A demographic survey of the Aboriginal population of the Northern Territory, with special reference to Bathurst Island Mission. Occasional Papers in Aboriginal Studies No. 1. Canberra: Australian Institute of Aboriginal Studies.

Jones, F. L. (1965). The demography of the Australian Aborigines. International Social Science Journal,17(2), 232-245.

Jones, F. L. (1970). The structure and growth of Australia's Aboriginal population. Aborigines in Australian society series. Canberra: ANU Press.

Jones, F. L. (1972). Fertility patterns among Aboriginal Australians. Human Biology in Oceania,1(4), 245-254.

Jones, F. L. (1973). Racial and ethnic minorities: The case of the Aboriginal Australians. Paper presented to the conference of the International Union for the Scientific Study of Population, Liège, August.

Kitaoji, Y. (1976). Family and social structure among Aborigines in Northern New South Wales. Ph.D. thesis, Australian National University.

Malinowski, B. (1913). The family among the Australian Aborigines: A sociological study. London: University of London Press. 
National Population Inquiry. (1975). Population and Australia: A demographic analysis and projection. First report of the national population inquiry (Vol. 2). Canberra: Australian Government Publishing Service.

National Population Inquiry. (1978). Population and Australia: Recent demographic trends and their implications. Supplementary Report. Canberra: Australian Government Publishing Service.

O'Donnell, J., \& Raymer, J. (2015). Identification change and its effect on projections of the Aboriginal and Torres Strait Islander population in Australia. Journal of Population Research, 32(3-4), 297-319.

Ross, K. (1999). Population issues, indigenous Australians 1996. Catalogue 4708.0. Canberra: Australian Bureau of Statistics.

Shapiro, W. (1979). Social organization in Aboriginal Australia. Canberra: Australian National University Press.

Smith, L. R. (1980a). Aboriginal vital statistics: An analysis of trends. Aboriginal Health Bulletin No. 1. Canberra: Australian Government Publishing Service.

Smith, L. R. (1980b). The Aboriginal population of Australia. Canberra: The Academy of the Social Sciences in Australia.

Smith, H. M., \& Biddle, E. H. (1975). Look forward, not back: Aborigines in metropolitan Brisbane 1965-1966. Aborigines in Australian society series No. 12, Canberra: ANU Press.

Stephens, M. (2003). White without soap: Philanthropy, caste and exclusion in colonial Victoria 18351888: A political economy of race. Ph.D. thesis, Department of History, University of Melbourne.

Stephens, M. (2014). Infanticide at Port Phillip: Protector William Thomas and the witnessing of things unseen. Aboriginal History,38, 109-130.

Tesfaghiorghis, H. (1996). Is Aboriginal fertility on the decline? Journal of the Australian Population Association,13(2), 153-167.

Thomson, N. (1990). Trends in Aboriginal infant mortality. In A. Gray (Ed.), A matter of life and death: Contemporary Aboriginal mortality (pp. 1-8). Canberra: Aboriginal Studies Press.

Zhang, G. (2014). Exploring methods to estimate the intercensal population of Aboriginal and Torres Strait Islander Australians. Catalogue 1352.0.55.140. Canberra: Australian Bureau of Statistics.

Zlotnik, H., \& Hill, K. (1981). The use of hypothetical cohorts for estimating demographic parameters under conditions of changing fertility and mortality. Demography, 18(1), 103-122.

Publisher's Note Springer Nature remains neutral with regard to jurisdictional claims in published maps and institutional affiliations. 